OPEN ACCESS

Edited by:

Jingting $L i$,

Sun Yat-sen University, China

Reviewed by:

Yuji Mishina,

University of Michigan, United States

Abbas Jafari,

University of Copenhagen, Denmark

Ye Li,

University of Michigan, United States

*Correspondence:

Yu Shi

yushi1105@scu.edu.cn

Specialty section:

This article was submitted to

Stem Cell Research,

a section of the journal

Frontiers in Cell and Developmental

Biology

Received: 05 November 2021

Accepted: 10 December 2021

Published: 05 January 2022

Citation:

Shen F and Shi Y (2022) Recent Advances in Single-Cell View of

Mesenchymal Stem Cell in Osteogenesis.

Front. Cell Dev. Biol. 9:809918. doi: 10.3389/fcell.2021.809918

\section{Recent Advances in Single-Cell View of Mesenchymal Stem Cell in Osteogenesis}

\author{
Fangyuan Shen and Yu Shi*
}

State Key Laboratory of Oral Diseases and National Clinical Research Center for Oral Diseases, West China Hospital of Stomatology, Sichuan University, Chengdu, China

Osteoblasts continuously replenished by osteoblast progenitor cells form the basis of bone development, maintenance, and regeneration. Mesenchymal stem cells (MSCs) from various tissues can differentiate into the progenitor cell of osteogenic lineage and serve as the main source of osteoblasts. They also respond flexibly to regenerative and anabolic signals emitted by the surrounding microenvironment, thereby maintaining bone homeostasis and participating in bone remodeling. However, MSCs exhibit heterogeneity at multiple levels including different tissue sources and subpopulations which exhibit diversified gene expression and differentiation capacity, and surface markers used to predict cell differentiation potential remain to be further elucidated. The rapid advancement of lineage tracing methods and single-cell technology has made substantial progress in the characterization of osteogenic stem/progenitor cell populations in MSCs. Here, we reviewed the research progress of scRNA-seq technology in the identification of osteogenic markers and differentiation pathways, MSC-related new insights drawn from single-cell technology combined with experimental technology, and recent findings regarding the interaction between stem cell fate and niche in homeostasis and pathological process.

Keywords: mesenchymal stem cells, osteogenesis, lineage tracing, single-cell, niche

\section{INTRODUCTION}

The bone formation depends on the activation and recruitment of osteogenic stem/progenitor cells during bone development, reconstruction, and fracture repair. During embryogenesis, mesodermderived limb bud mesenchymal progenitors (LMPs) differentiate into osteochondrogenic lineages and generate primitive cartilage templates. After LMPs differentiate into cartilage, long bones are built through endochondral ossification. At the beginning of primary ossification center formation, perichondrial progenitor cells and blood vessels extend into cartilage lacuna left by the degeneration

\footnotetext{
Abbreviations: LMPs, Limb Bud Mesenchymal Progenitors; POC, Primary Ossification Center; SSCs, Skeletal Stem Cells; OCPs, Osteo-chondrogenic Progenitors; MSCs, Mesenchymal Stem Cells; mSSCs, Mouse Skeletal Stem Cell; WPC, Weeks Post Conception; eSSPCs, Embryonic Skeletal Stem/Progenitor Cells; NCDCs, Neural Crest-derived Cells; PDLSCs, Periodontal Ligament Stem Cells; P-SSCs, Periosteal Skeletal Stem Cells; BMSCs, Bone Marrow Mesenchymal Cells; PSCs, periosteal Stem Cell; OLCs, Osteolineage Cells; mpMSCs, Mesenchymal Stem Cells From The Metaphysis; dpMSCs, Mesenchymal Stem Cells From The Diaphysis; SuSCs, Suture Stem Cells; MMPs, Metaphyseal Mesenchymal Progenitor Cells; BMP, Bone Morphogenetic Protein; CTSK, Cathepsin K; Scal, Stem Cell Antigen 1; CXCL12, C-X-C Motif Chemokine Ligand 12; EMPs, Early Mesenchymal Progenitors; TME, Tumors Microenvironment; ECM, Extracellular Matrix; SSPCs, Skeletal Stem/progenitor Cells; HO, Heterotopic Ossification.
} 
of chondrocytes in the cartilage template, and then new bone marrow is formed (Maes et al., 2010; Ono et al., 2014). In postnatal life, bone is a dynamic tissue that is constantly being resorbed and remodeled. The undifferentiated MSCs in the bone marrow stroma are ancestors of osteoprogenitor cells and preosteoblasts, and under the regulation of Runt-related transcription factor $2($ Runx2) and Osterix (Osx) (Nakashima et al., 2002; Lian et al., 2006), they differentiate into mature osteoblasts which have a limited lifespan and are constantly replenished by osteogenic precursor cells.

MSCs have long been regarded as a direct source of osteogenic lineage progenitor cells in bone tissue. Their source is complex and correlates with stage and tissue specificity. MSC can be isolated from tissues such as teeth, bone marrow, adipose, umbilical cord, etc. The distribution, differentiation direction, immunosuppressive ability of MSCs subgroups from different sources are various, and the expression pattern also changes with age. Extensive studies have shown that MSCs are heterogeneous mixtures of multiple stem cell lineages, which can differentiate into osteoblasts, chondrocytes, and bone marrow stromal cells, fat cells, muscle cells, and endothelial cells (Uccelli et al., 2008; Chen et al., 2019). To identify cell subsets with specific functions in heterogeneous MSCs, cell surface markers are continuously explored. However, the non-negligible heterogeneities and lack of stage-specific markers hindered the identification and positioning of cell types and formed a significant barrier to our understanding of MSC populations. Until 2018, single-cell and lineage tracing technology was used to identify self-renewing and multipotent skeletal stem cells (SSCs) which could only differentiate into the progenitor of the osteogenic lineage (osteoprogenitors, chondroprogenitors, and progenitor cells of stroma) (Chan et al., 2018). With the emergence of numerous MSC-related studies, researchers have meticulously named the subgroups of MSCs such as embryonic Skeletal Stem/progenitor Cell (eSSPC), Bone Marrow Mesenchymal Cell (BMSC), Periosteal Stem Cell (PSC), etc., based on tissue origin, the developmental stage of donors, and differentiation characteristics. Possessing functional properties consistent with MSC, these renamed subgroups belong to the category of MSC.

Due to the rapid progress of mouse lineage-tracking techniques and single-cell RNA sequencing (scRNA-seq), researchers have made extraordinary progress in identifying and characterizing MSC heterogeneity and reconstructing osteogenic regulatory networks. To date, MSCs have been detected in growth plate cartilage, bone marrow stroma, the superficial layer of meniscus, bone surface resting-state bone lining cells and specialized fibroblasts in the craniofacial structure and have been characterized by several markers (i.e., leptin receptor $[L e p R]$, cathepsin $\mathrm{K}[C t s k]$, gliomaassociated oncogene homolog 1 [Gli1], and platelet-derived growth factor receptor $[P d g f r]$, etc.) in vivo (Maruyama et al., 2016; Yue et al., 2016; Shi et al., 2017; Mizuhashi et al., 2018; Baryawno et al., 2019; Bohm et al., 2019; Ortinau et al., 2019; Ponte et al., 2020; Wei et al., 2021; Zhang et al., 2021). In this review, we summarized the heterogeneity of MSCs derived from limb buds and postnatal distinct hard tissues as determined by single-cell resolution studies and the biologic functions and characteristics of new labeled stem/progenitor subpopulations. We also focused on the research progress on the osteogenic subpopulation of cre-targeted MSCs and the interaction between the osteogenic niche and precursor cells.

\section{TRADITIONAL MSCS IDENTIFICATION METHODS}

Current knowledge of MSCs mainly originates from experiments with human and rodent bone marrow cells. In vitro cultivation and allogeneic cell transplantation have become the gold standard for identifying MSC. Early studies verified the adherence, the ability to form fibroblast colonies (CFU-F), and the osteogenic ability after allograft transplantation to identify the proliferation and trilineage differentiation potential of MSCs (Cao et al., 2020). Flow cytometry was used to screen cell surface markers (L. Ramos et al., 2016). In recent years, many studies have begun to use lineage-tracing techniques to track the activity of MSC maker+ cells in transgenic mice, thereby identifying a series of MSC markers, such as Grem1 (Worthley et al., 2015), Gli1 (Shi et al., 2017), LepR (Zhou et al., 2014), Pthrp (Mizuhashi et al., 2018), Sox9 (Kuwahara et al., 2019), Cxcl12 (Matsushita et al., 2020), Prx1 (Moore et al., 2018), etc. However, the proposed surface markers generally have the problem of low specificity, and as the physiological state and the microenvironment change, MSC markers will alter accordingly. With source diversity, MSCs can be isolated from hard tissues such as teeth, bone marrow, and craniofacial sutures. There is evidence that MSCs from different tissues are divergent (Figure 1) (Sharpe, 2016; Huang et al., 2019; Zhou et al., 2019). Although different tissue-derived MSC all meet the minimum standards for defining MSCs, their transcriptome pattern and multipotential differentiation capacity may also be vastly different (Table 1). Therefore, based on the complex expression alteration of MSC, a single surface marker is not enough to describe the heterogeneous MSC population.

\section{SCRNA-SEQ-BASED MSC IDENTIFICATION AND FUNCTION ASSESSMENT}

scRNA-seq profile gene expression at single-cell resolution, which is ideally suited to explore the heterogeneity of MSCs. The key to scRNA-seq technology is single-cell isolation and independent library construction. Using droplet-based microfluidics technology, single cell and gel beads containing a barcode, unique molecular index, primers, and enzymes were wrapped in an oil droplet through a microfluidic chip (Zhou et al., 2021). The barcode in each oil droplet is a unique DNA sequence, thus allowing the distinction of the source of the target sequence during sequencing (Figure 2). Therefore, researchers achieve large-scale single-cell isolation and routine profiling of thousands of cells via constructing libraries at one time. The scRNA-seq data set analysis of the MSC population roughly follows three main steps (Andrews et al., 2021). First, after quality control and normalization, the cells are divided into 


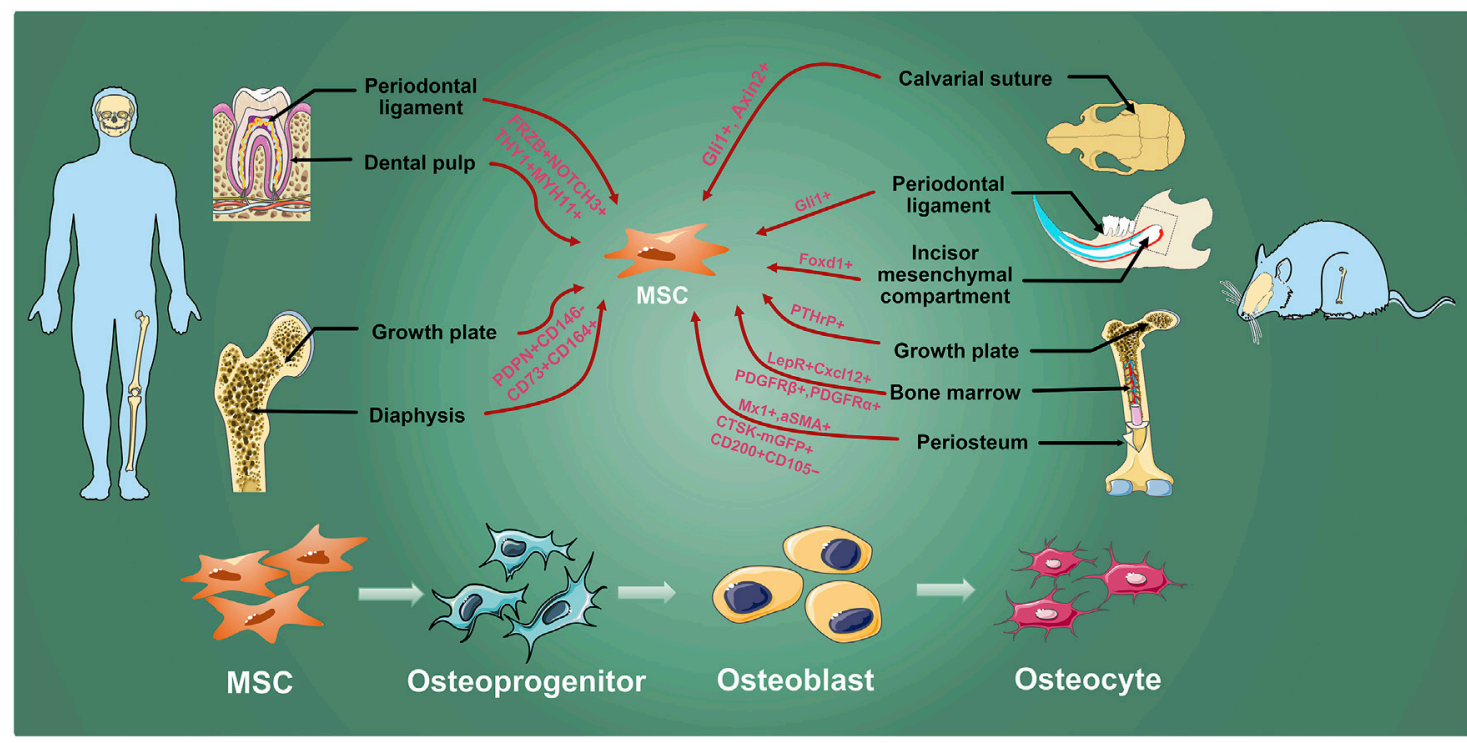

FIGURE 1 | MSC inhabit in various hard tissues. Osteogenic MSCs which are labeled by researchers with different genes exist in human molars and long bones, and mouse calvarial sutures, incisors, molars, and long bones. They are finally differentiated into osteocyte through osteoprogenitors and osteoblasts to involve in maintaining bone homeostasis, growth, development, and injury repair.

multiple subpopulations through dimensionality reduction and unsupervised clustering. Subpopulations are assigned cell types based on their gene expression patterns and prior knowledge. Second, analysis of cell heterogeneity within each cell type can identify MSC subpopulations with distinct cell states and expression programs. Genes that are differentially expressed between subpopulations can be regarded as potential markers. Third, among MSC-related studies, single-cell sequencing objects are typically a heterogeneous cell population, which emerges from the development or differentiation process of pluripotent stem cells making fate decisions and transitioning to specific cell types through intermediate cell states. Pseudotime inference constructs a pseudo-temporal process trajectory to order cells based on the gradual transition of transcriptomes. In MSC-related cases, these trajectories measure the relative progression of each cell along the development or differentiation process, allowing us to understand the pseudo-temporal behavior without explicit time series data (Campbell and Yau, 2018; Herring et al., 2018). Using scRNA-seq, researchers could subdivide MSCs population according to transcription information of individual cells, and predict potential gene markers to label cell populations by differential analysis, which is quite beneficial for finding suitable MSCs groups with different clinical needs of the stem cell therapy.

The recently emerging single-cell epigenome-, genome-, and proteome-sequencing technologies also provide promising directions (Nam et al., 2021). Li et al. (2018) team systematically describes the dynamic changes of the development of mouse preimplantation embryos from five epigenome levels (chromatin status, DNA methylation, copy number variation, and ploidy). Ai et al. (2019) and Wang et al. (2019) used independently developed CoBATCH and sc-
itChIP technologies to profile the heterogeneity of endothelial lineage development, differentiation, and function in ten different tissues of mouse embryos. Chaligne et al. (2021) combined singlecell sequencing of DNA methylation, scRNA-seq and targeted genotyping to analyze diffuse gliomas, revealing dysregulated epigenetic mechanisms underlying gliomagenesis. Single-cell multi-omics integrated analysis is a powerful tool to study stem cell development, but there is still a gap in MSC-related research, and remains an uncovered space for future research.

\subsection{Identification of MSCs in Embryonic and Fetal Limb Buds}

In the initial stage of limb bud development, LMPs are composed of distinct progenitor cell types, which show heterogeneous characteristics and differentiated states (Table 1) (Norrie et al., 2014; Ornitz and Marie, 2015; Tickle and Towers, 2017). SOX9expressing LMPs differentiate into cartilage and are regarded as osteochondrogenic progenitors (OCPs) (Akiyama et al., 2005), which generate primitive cartilage templates and then form limb bones through endochondral ossification. In contrast, another method of bone formation, intramembranous ossification builds the most of craniomaxillofacial bones. During this process, bone develops directly from sheets of mesenchymal tissue without the formation of intermediate cartilage.

In 2019, Reinhardt et al. (2019) identified the molecular characterization of various mesenchymal progenitor subpopulations in the early forelimb buds of mice (E10.5E10.75). They found that $S O X 9^{-} J A G 1^{+}$cells that resided in the distal posterior of mesenchyme were the most immature progenitor cells, which mainly depended on Sonic Hedgehog and apical ectodermal ridge-Fibroblast Growth Factor signaling 
TABLE 1 | Characterization of embryonic and hard tissue-derived stem/progenitor cell (WPC, weeks post conception; yo, years old).

\begin{tabular}{|c|c|c|c|c|c|}
\hline Species & Localization & Age & Cell & Marker & Reference \\
\hline \multirow[t]{5}{*}{ Human } & Limb buds & 5 WPC & Osteo-chondrogenic progenitorss & SOX9low PDGFRa ${ }^{\text {hi }}$ & $\begin{array}{l}\text { He et al. } \\
\text { (2021a) }\end{array}$ \\
\hline & Limb bud long bones & 8 WPC & $\begin{array}{l}\text { Embryonic skeletal stem/progenitor } \\
\text { cells }\end{array}$ & 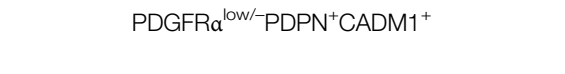 & $\begin{array}{l}\text { He et al. } \\
\text { (2021a) }\end{array}$ \\
\hline & Embryonic calvarium & 8 WPC & Neural crest-derived cells & 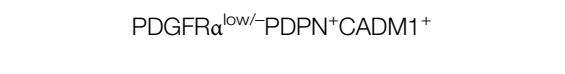 & He et al. \\
\hline & $\begin{array}{l}\text { Third molar dental pulp and } \\
\text { periodontal ligament }\end{array}$ & 18-35уо & Mesenchymal stem cells & $\mathrm{FRZB}^{+} \mathrm{NOTCH}^{+} \mathrm{THY}^{+}{ }^{+} \mathrm{MYH} 11^{+}$ & $\begin{array}{l}\text { Pagella et al. } \\
(2021)\end{array}$ \\
\hline & $\begin{array}{l}\text { Femur growth plate and } \\
\text { diaphysis }\end{array}$ & $\begin{array}{l}17 \text { weeks } \\
\text { fetal }\end{array}$ & Human-skeletal stem cells & $\mathrm{PDPN}^{+} \mathrm{CD} 146^{-} \mathrm{CD}^{-} 3^{+} \mathrm{CD} 164^{+}$ & $\begin{array}{l}\text { Chan et al. } \\
(2018)\end{array}$ \\
\hline \multirow[t]{14}{*}{ Mice } & Forelimb buds & $\begin{array}{l}\text { E10.5- } \\
\text { E10.75 }\end{array}$ & Osteo-chondrogenic progenitors & Sox9 PDGFRa ${ }^{\text {hi }}$ & $\begin{array}{l}\text { Reinhardt } \\
\text { et al. (2019) }\end{array}$ \\
\hline & Forelimb buds & $\begin{array}{l}\text { E10.5- } \\
\text { E10.75 }\end{array}$ & $\begin{array}{l}\text { Transition betweenlimb bud } \\
\text { mesenchymal progenitors and } \\
\text { osteo-chondrogenic progenitors }\end{array}$ & Sox9-PDGFRa ${ }^{\text {hi }}$ & $\begin{array}{l}\text { Reinhardt } \\
\text { et al. (2019) }\end{array}$ \\
\hline & Forelimb buds & $\begin{array}{l}\text { E10.5- } \\
\text { E10.75 }\end{array}$ & Limb bud mesenchymal progenitors & Sox9-JAG1 ${ }^{+}$ & $\begin{array}{l}\text { Reinhardt } \\
\text { et al. (2019) }\end{array}$ \\
\hline & Hind limb & E12.5 & Musculoskeletal stem cells & $\mathrm{Scx}^{+} \mathrm{Hoxd} 13^{+}$ & $\begin{array}{l}\text { Yin et al. } \\
(2020)\end{array}$ \\
\hline & Femur & Postnatal & Mouse skeletal stem cells & CD45-Ter119- Tie $^{-}$AlphaV ${ }^{+}$Thy $^{-} 6 \mathrm{C3}^{-} \mathrm{CD}^{-} 105^{-} \mathrm{CD}^{-} 00^{+}$ & $\begin{array}{l}\text { Chan et al. } \\
(2015)\end{array}$ \\
\hline & $\begin{array}{l}\text { Incisor mesenchymal } \\
\text { compartment near the labial } \\
\text { cervical loop }\end{array}$ & 2-4 months & Mesenchymal stem cells & Foxd $1^{+}$ & $\begin{array}{l}\text { Krivanek et al } \\
\text { (2020) }\end{array}$ \\
\hline & $\begin{array}{l}\text { Molar periodontal ligament } \\
\text { apical }\end{array}$ & Adult & Periodontal ligament stem cells & $\mathrm{Gli}^{+}$ & $\begin{array}{l}\text { Men et al. } \\
(2020)\end{array}$ \\
\hline & $\begin{array}{l}\text { The resting zone of growth } \\
\text { plate }\end{array}$ & Postnatal & Skeletal stem cells & PTHrP ${ }^{+}$ & $\begin{array}{l}\text { Mizuhashi } \\
\text { et al. (2018) }\end{array}$ \\
\hline & $\begin{array}{l}\text { The periphery of the growth } \\
\text { plate immediately adjacent to } \\
\text { the perichondrium }\end{array}$ & $\begin{array}{l}\text { Fetal and } \\
\text { neonatal }\end{array}$ & $\begin{array}{l}\text { Mesenchymal precursor cells/ } \\
\text { chondrocytes }\end{array}$ & $\mathrm{PTHrP}^{+}$ & $\begin{array}{l}\text { Mizuhashi } \\
\text { et al. (2019) }\end{array}$ \\
\hline & Metaphysis and diaphysis & 3 week & $\begin{array}{l}\text { Mesenchymal stromal cells from the } \\
\text { metaphysis and diaphysis }\end{array}$ & $\mathrm{PDGFR}^{+}, \mathrm{PDGFR}^{+}$ & $\begin{array}{l}\text { Sivaraj et al. } \\
(2021)\end{array}$ \\
\hline & Metaphysis and diaphysis & Postnatal & Bone marrow stromal cells & LepR $^{+}$ & $\begin{array}{l}\text { Shu et al. } \\
(2021)\end{array}$ \\
\hline & $\begin{array}{l}\text { Periosteum in the metaphysis } \\
\text { and diaphysis }\end{array}$ & Adult & Periosteal skeletal stem cells & $\mathrm{Mx}^{+}, \mathrm{aSMA}^{+}$ & $\begin{array}{l}\text { Sivaraj et al. } \\
(2021)\end{array}$ \\
\hline & $\begin{array}{l}\text { Bone marrow stromal of femur } \\
\text { and tibia }\end{array}$ & $6-8$ weeks & Mesenchymal stem cells & $\mathrm{LepR}^{+} \mathrm{Cxcl} 12^{+}$ & $\begin{array}{l}\text { Baryawno } \\
\text { et al. (2019) }\end{array}$ \\
\hline & Long bone and calvarium & Postnatal & Periosteal stem cells & CTSK-mGFP ${ }^{+} \mathrm{CD}_{200^{+} \mathrm{CD} 105^{-}}$ & $\begin{array}{l}\text { Debnath et al } \\
\text { (2018) }\end{array}$ \\
\hline
\end{tabular}

to maintain their proliferative and undifferentiated state, through Grem1-mediated Bone Morphogenetic Protein (BMP) antagonism to avoid BMP-induced apoptosis (Michos et al., 2004). In contrast, $S O X 9^{+} P D G F R \alpha^{\text {hi }}$ OCPs are sensitive to BMP signaling in the mesenchyme core where limb buds will initially form, while changing from proliferative signals to responding to differentiation signaling. This kind of signal response transformation is a necessary condition for transformation from LMPs to OCPs. As a transition between

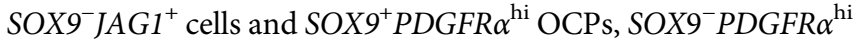
cells highly express T-Box transcription factor 2 (TBX2) which is involved in the repression of Grem1, enhancing the activity of BMP signals and endow LMPs with the potential to form limb buds (Michos et al., 2004; Farin et al., 2013). For murine hindlimb, Yin et al. (2020) named a cluster, composed predominantly of E12.5 cells which highly express scleraxis $(S c x)$ and homeobox protein hox-D13 (Hoxd13) as musculoskeletal stem cells. $S c x^{+}$musculoskeletal stem cells can generate soft tissue (myocytes, meniscus cells, and tenocytes) and hard tissue (chondrocytes and osteocytes) progenitors, marked by $S c x^{+}$Collal $^{+}$and $S c x^{+} S o x 9^{+}$respectively. However, Kelly et al. (2020) observed faint and scattered expression of $S c x$ at a time point after E13.5 and no expression in E11.5 and E13.5, and did not detect clusters marked by $S c x$ from scRNA-seq analysis. The peak of $S c x$ expression appeared in the middle of the trajectory (around E12.5). It has been reported, although $S c x$ is transiently expressed in the chondrogenic lineage and entheseal cartilage, it is particularly important for the correct integration of musculoskeletal components (Blitz et al., 2013; Zelzer et al., 2014; Killian and Thomopoulos, 2016). Therefore, we speculated that $S c x$, a key transcription factor that regulates musculoskeletal tissue morphogenesis, may be only transiently expressed around E12.5, but the mechanism of $S c x$ action remains unknown, and needs to be further investigated.

Human embryonic cells continuously differentiate from limb bud mesenchymal progenitor cells into OCPs, which gives rise to 


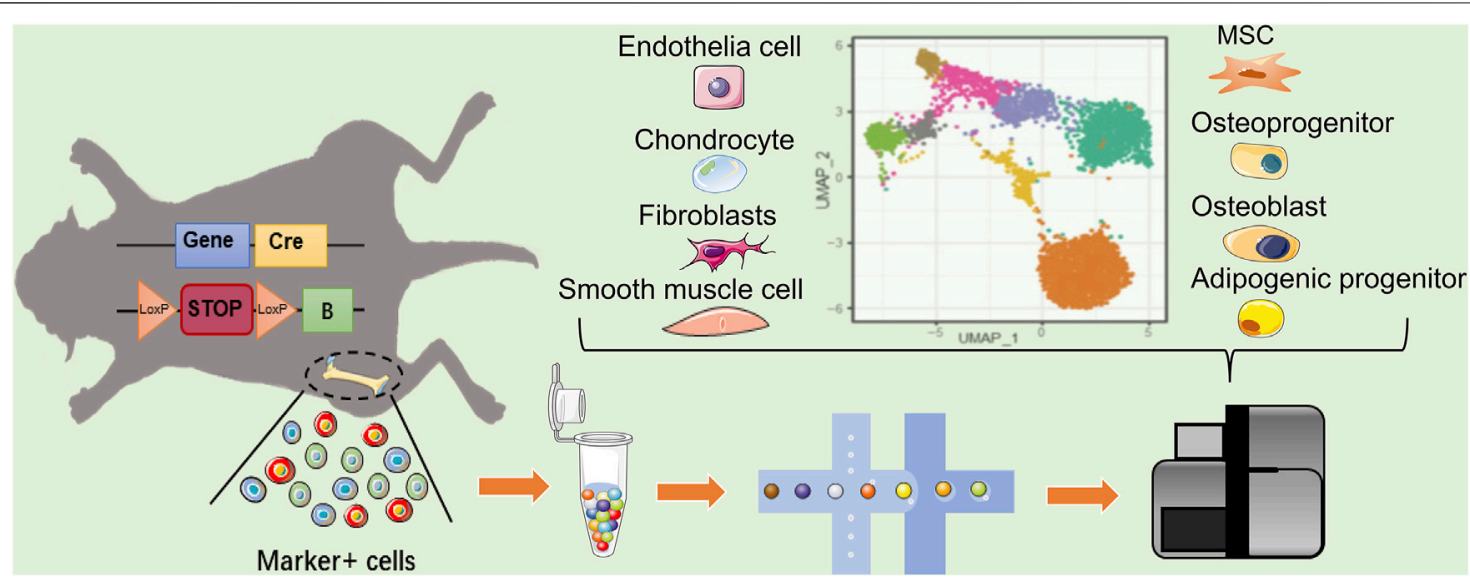

FIGURE 2 |Single cell reveals the heterogeneity of MSCs markers targeting cells. In mice with Cre-loxP recombination system, the MSC markers gene expressingcells will be fluorescently labeled. When two loxP sites exist in the same DNA strand with the same orientation, terminator between two loxP will be removed by Cre, allowing the fluorescent protein to be expressed. The heterogeneity of labeled MSCs can revealed by scRNA-seq. In addition to MSC, the existing MSC marker-labeled cell population may include Osteo- and adipo-lineage cells, chondrocytes, epithelial cells, and fibroblast smooth muscle cells, etc. Blue square: MSC marker gene; yellow square: cyclization recombination enzyme gene; red rounded rectangle: stop codon; orange triangle: specific recognition site of Cre recombinase; green square: fluorescent reporter

osteogenic and chondrogenic lineages. He et al. (2021a) identified four mesenchymal cell subpopulations (Limb Bud Mesenchyme1-3 and OCP) in human limb buds at 5 weeks post-conception (WPC). Similar to mouse OCPs, human limb bud OCPs (SOX $9^{\text {low } P D G F R ~} \alpha^{\text {hi }}$ ) were located in the core mesenchyme and possessed chondrogenic potential. At 8WPC, a cluster marked by cell adhesion molecule 1 (CADM1) was assigned as perichondral embryonic skeletal stem/progenitor cells (eSSPCs); these cells are self-renewable and capable of generating osteochondral lineage. At the same developmental stage, a group of neural crest-derived stem/progenitor cells shared immunophenotype and transcriptional network as long bonederived eSSPC were identified in the calvaria sagittal suture. They were characterized by the gene expression signature of intramembranous ossification, which mediates the development of the human craniofacial skeleton. In 2018, Chan et al. (2018) revealed markers of human SSC $\left(P D P N+C D 146-C D 73^{+} C D 164+\right)$ via scRNA-seq performed on a 17-week fetal femur growth plate and diaphysis. The isolated human SSCs displayed self-renewal abilities in vitro and could generate multilineage ossicles composed of bone, cartilage, and stromal progenitors under the renal capsule of NSG mice in vivo.

\subsection{Hard Tissue-Derived MSCs in Postnatal Stages}

Limb bones and MSCs residing in them primarily originate from the lateral plate mesoderm during embryogenesis, which create bone tissue by means of endochondral ossification. Neural crest cells located in the neuroectoderm are the principal source of craniofacial bones, cartilage and teeth. The neural crest-derived MSCs residing in the craniofacial region possess characteristics of multidirectional differentiation and low immunogenicity, which are comparable with the mesoderm-derived MSC, but the neural crest-derived MSCs are mostly involved in endochondral ossification.

\subsubsection{Dental-Derived MSCs}

Growing mouse incisors contains a continuously replenished mesenchymal compartment composed of dentin-secreting odontoblasts and various types of pulp cells. Krivanek et al. (2020) used single-cell technology to study the heterogeneity of the mesenchymal compartment in mouse incisors. They found a apical pulp subtype marked by Smoc2 and Sfrp2, which was specifically located in the apical pulp area in cervical loops and included potential stem/progenitor cells that express genes related to self-renewal such as Gli1 and Thy1. Foxd $1^{+}$multipotent MSCs which mainly generated periodontoblastic pulp cells and odontoblasts were screened out, and Foxd1-traced cells were only detected in the mesenchymal compartment adhering to the labial cervical loop, revealing the pluripotency of Foxd $1^{+}$MSCs and spatially constrained structure of the self-renew in growing mouse incisors. By comparing the cell subtypes of human apical and mouse distal incisor pulp, they inferred that although cell types are similar, evolutionary differences in gene expression programs that regulate development and homeostasis of dental pulp excluded the possibility of establishing precisely homologous subpopulation in the dental pulp between mouse and human (Krivanek et al., 2020). In adult mouse molar periodontal ligament, $\mathrm{Gli}^{+}$cells enriched in the apical region are regarded as periodontal ligament stem cells, which can generate periodontal ligament, alveolar bone, and cementum, under Wnt signaling-mediated regulation (Men et al., 2020). Pagella et al. (2021) marked MSCs by highly expressed FRZB, NOTCH3,THY1, and MYH11 in the dental pulp and periodontium of human third molars. In addition, CCL2 and collagen-encoding genes were significantly higher in periodontal 
MSCs than in dental pulp. In contrast, pulp MSCs expressed higher levels of CXCL14 and RARRES1 than periodontal MSCs. They revealed that the MSCs in the dental pulp and periodontium, both as neural crest-derived cells, shared a common phenotype, and contained stem cells with high regenerative potential, showing overall homology, which was consistent with the previous study (Luan et al., 2009). The specificity of the respective niche is a potential source of the divergence in MSC function, which direct periodontal and dental pulp MSC to fibroblastic-like and osteogenic fate, respectively.

\subsubsection{Long Bone-Derived MSCs}

The growth plate provides a continuous source of MSCs for endochondral ossification to construct a stromal compartment to maintain the expansion of bones and bone marrow space. PTHrP-expressing chondrocytes within the resting zone of the growth plate are considered one of the sources of SSCs, as they not only express a panel of skeletal stem/progenitor markers and possess characteristics of SSCs in vitro but also continuously form columnar chondrocytes that can generate osteoblasts and marrow stromal cells beneath the growth plate (Mizuhashi et al., 2018). In addition, the marginal chondrocytes around the growth plate behave as transient mesenchymal precursor cells, committed osteoblasts, and marrow stromal cells in vivo. Mizuhashi et al. (2019) performed single-cell sequencing on Col2al-creERmarked chondrocytes in neonatal growth plates. They revealed that column-forming chondrocyte clusters from the growth plate of upper and lower region were marked by Ucma and Prg4, respectively; cluster abundant in tdTomato-WPRE was assigned as borderline chondrocytes between the upper and lower zone expressing Pthrp and Cxcl14 and no hypertrophic markers. $\mathrm{PTHrP}^{+}$cells tracked non-self-renewing borderline chondrocyte subsets, which can give rise to short-lived osteoblasts and CXCL12-abundant reticular cells in the marrow cavity of long bone metaphysis (Mizuhashi et al., 2019).

MSCs in the periosteum are one of the major reservoirs of osteoprogenitor cells. Clinical and experimental data prove that the periosteum plays an essential role in postnatal bone growth, maintenance, and injury repair (Chaudhary et al., 2016; Debnath et al., 2018; Duchamp de Lageneste et al., 2018; Xiao et al., 2020). In adult mice, $M x 1$ - and aSMA-labeled periosteal SSCs (P-SSCs) represent a unique lifelong sustainably regenerative stem cell group which serves as the main force for cortical bone regeneration and damage healing (Ortinau et al., 2019). There is evidence that P-SSCs contribute more to damage repair than bone marrow mesenchymal cells (BMSCs) (Worthley et al., 2015; Ortinau et al., 2019). With distinctive CCL5-dependent migration mechanism, $M x 1^{+}$P-SSCs were rapidly recruited to injury area and generated osteoblasts, the number of which far exceeds of Greml $^{+}$bone marrow SSCs-derived (Ortinau et al., 2019). Besides, clusters of progenitor/stem cell and osteoblast were detected from scRNA-seq data of CTSK-mGFP+ periosteal mesenchymal cells. And in Ctsk-cre; mTmG reporter mice,

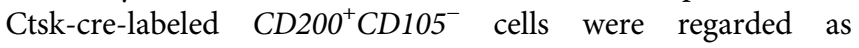
periosteal MSCs (PSCs) because of their capacity for "trilineage" differentiation, self-renewal and generation of the entire spectrum of CTSK-mGFP ${ }^{+}$cells (bone, cartilage, stromal precursor/progenitor cells) (Debnath et al., 2018). PSCs specialize in intramembranous bone formation (Colnot, 2009), whereas P-SSCs display endochondral ossification and intramembranous bone formation.

BMSCs are the most commonly used stem cell in cell therapy clinical trials because of their ethical acceptability and accessibility. Researchers have characterized the heterogeneity and subpopulations of MSCs in different parts of the bone marrow cavity based on genetic fate tracking and single-cell sequencing (Severe et al., 2019; Tikhonova et al., 2019; AlSabah et al., 2020; Lu and Qiao, 2021). Baryawno et al. (2019) defined MSC clusters highly express LepR and Cxcl12, and two MSC-descendent osteolineage cells (OLC) subgroups express osteocalcin (Bglap). These two OLC subgroups are derived from distinct origins. The subpopulation composition in OLC1 exhibited an osteolineage continuum from committed osteolineage LepR-MSC-4 in bone marrow, and expressed the key hematopoiesis-regulated cytokines, whereas OLC-2 mostly derived from bone, with no hematopoietic support potential. Besides, researchers have revealed temporal and spatial distinctions between BMSCs from the metaphysis (mpMSCs) and diaphysis (dpMSCs). Postnatal mpMSCs possessed multipotent properties. Clusters representing mpMSC, dpMSC, osteoprogenitor cells, osteoblasts, and proliferating BMSCs were identified in bone marrow. mpMSCs were placed in the center of pseudo-time trajectory, which directed to proliferating BMSC, dpMSC, and osteoprogenitor cell respectively (Sivaraj et al., 2021). PDGFR $\alpha^{+} \beta^{+}$mpMSCs contained progenitors that gave rise to bone-forming osteoblast lineage cells, $L e p R^{+}$marrow stromal cells, and dpMSCs, whereas PDGFR $\alpha^{+}$dpMSCs from juvenile mice showed limited growth in vitro (Sivaraj et al., 2021). In addition, Chondrocytes and $\mathrm{Lepr}^{+}$BMSCs mediate longitudinal growth and transverse thickening of the bone before and after adolescence, respectively. (Shu et al., 2021) reported that osteoblasts are mainly emerged from $\mathrm{Acan}^{+}$ chondrocytes in the growth plate to realize bone lengthening before adolescence, whereas after adolescence, they primarily arise from LepR ${ }^{+}$BMSCs to achieve bone thickening.

\subsubsection{Craniofacial Skeleton-Derived MSCs}

In contrast to long bone endochondral ossification, the craniofacial skeleton is mainly formed through intramembranous ossification. As the main growth centers for craniofacial bone development, calvarial sutures preserve the population of MSCs that support craniofacial bone repair. Gli1 $^{+}$cells and Axin2 ${ }^{+}$cells within the suture mesenchyme are the major MSC populations in the craniofacial bone and are regarded as suture stem cells (SuSCs) (Zhao et al., 2015; Maruyama et al., 2016). SuSCs are endowed with stem cell characteristics during calvarial development and homeostatic maintenance and are directly involved in injury repair and regeneration. Ablation of $\mathrm{Gli}^{+}$and Axin2 $^{+}$cells leads to premature suture fusion (Zhao et al., 2015; Maruyama et al., 2016). However, the localization and responsible areas of Axin2 ${ }^{+}$ and $\mathrm{Gli1}^{+}$cells are different. Gli1 ${ }^{+}$SuSCs are distributed throughout the mesenchyme suture and other osteogenesis regions within the suture, whereas Axin2-expressing cells are 
TABLE 2 | Lineage-tracing mouse transgenic lines with stem/progenitor markers for scRNA-seq.

\begin{tabular}{|c|c|c|c|c|c|}
\hline Driver & $\begin{array}{l}\text { Representative cre- } \\
\text { marked } \\
\text { cells }\end{array}$ & $\begin{array}{l}\text { Single-cell sequencing } \\
\text { object }\end{array}$ & Subclusters & $\begin{array}{l}\text { Time points } \\
\text { of induction }\end{array}$ & Reference \\
\hline $\begin{array}{l}\text { Gli1-CreERT2; } \\
\text { tdTomato }\end{array}$ & $\begin{array}{l}\text { Metaphyseal } \\
\text { mesenchymal } \\
\text { progenitor cells }\end{array}$ & 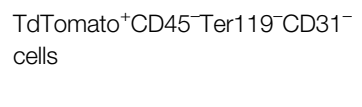 & $\begin{array}{l}\text { Osteoblasts, preosteoblasts, } \\
\text { chondrocyte-like osteoprogenitors and } \\
\text { marrow adipogenic lineage progenitors }\end{array}$ & $\begin{array}{l}\text { Three consecutive } \\
\text { days at } \\
4 \text { weeks old }\end{array}$ & $\begin{array}{l}\text { Shi et al. } \\
(2021)\end{array}$ \\
\hline $\begin{array}{l}\text { Pdgfr } \beta \text {-CreERT2; } \\
\text { Rosa26-mTmG }\end{array}$ & Pdgfr $\beta+B M S C s$ & $\mathrm{GFP}^{+}$cells & $\begin{array}{l}\text { BMSCs, chondrocytes, smooth muscle } \\
\text { cells, fibroblasts, hematopoietic cells }\end{array}$ & Postnatal day $1-3$ & $\begin{array}{l}\text { Bohm et al. } \\
(2019)\end{array}$ \\
\hline Ctsk-cre; mTmG & Periosteal stem cells & Metaphyseal CTSK-mGFP ${ }^{+}$cells & $\begin{array}{l}\text { Progenitor/stem cells, osteoblasts, Ly6a } \\
\text { and Acta2 expressing cells }\end{array}$ & $\mathrm{N} / \mathrm{A}$ & $\begin{array}{l}\text { Debnath et al. } \\
\text { (2018) }\end{array}$ \\
\hline $\begin{array}{l}\text { Cxcl12GFP/+; } \\
\text { Cxcl12-creER; } \\
\text { R26RtdTomato }\end{array}$ & $\begin{array}{l}\text { Cxcl12-creER+stromal } \\
\text { cells }\end{array}$ & $\mathrm{Cxcl12}-\mathrm{GFP}^{+}$cells & $\begin{array}{l}\text { Stromal (reticular cells and pre- } \\
\text { osteoblasts), endothelial, periosteal and } \\
\text { cells in cell cycle, clusters enriched for } \\
\text { mitochondrial and ribosomal genes }\end{array}$ & Postnatal day 21 & $\begin{array}{l}\text { Matsushita } \\
\text { et al. (2020) }\end{array}$ \\
\hline $\begin{array}{l}\text { Lepr-cre; LoxP- } \\
\text { tdTomato }\end{array}$ & LepR+ cells & Lepr-tdT cells & $\begin{array}{l}\text { Osteo-primed } L e p R^{+} \text {cells and adipocytic- } \\
\text { primed } L e p R^{+} \text {cells }\end{array}$ & $\mathrm{N} / \mathrm{A}$ & $\begin{array}{l}\text { Tikhonova } \\
\text { et al. (2019) }\end{array}$ \\
\hline
\end{tabular}

only limited to the middle part of suture mesenchyme, almost not adjacent to bone tissues. In addition, calvarial sutures contain SuSCs with the same immunophenotype as long bone-derived PSCs and share the same intramembranous osteogenesis pathway as PSCs (Debnath et al., 2018). Recently, researchers have successfully used $\mathrm{Glil}^{+}$MSCs to regenerate a functional cranial suture and ameliorate craniosynostosis in a mouse model (Yu et al., 2021). Hence, SuSCs are expected to bring new vitality to human craniosynostosis therapy.

\section{SCRNA-SEQ ON CRE-TARGETED MSCS IN TRANSGENIC MICE}

Lineage tracing is important in stem cell research, which through the Cre recombinase (Cre)-loxP system permanently marks specific cells and tracks the proliferation, differentiation, and migration activities of specific cells and their descendants in vivo. Several endogenous osteogenesis stem/progenitor cell populations were marked by the expression of Gli1, Osx, Ctsk, $P d g f r \beta$, etc. In recent years, researchers have used lineage tracing combine with fluorescence-activated cell sorting techniques to tag and sort MSCs based on a series of markers, and subsequently performed scRNA-seq on them, thereby realizing the reconstruction of cell development trajectories and parsing the regulation of fate-determining gene expression (Table 2).

Gli1, which encodes the transcriptional key effector of Hedgehog $(\mathrm{Hh})$, serves as a primary marker of MSCs. Gli1 ${ }^{+}$ cells continuously replenish osteoblasts for bone development and repair. Within craniofacial sutures, $\mathrm{Gli1}^{+}$cells were proposed as the major MSC population for craniofacial bone, responsible for the growth and injury repair. In postnatal mice, $\mathrm{Gli1}^{+}$cells inhabiting underneath the growth plate, were called metaphyseal mesenchymal progenitor cells, which can generate osteoblasts, adipocytes, and stromal cells in vivo and express Pdgfr $\alpha, L e p R$, and other MSC marker genes (Shi et al., 2017). Gli1 ${ }^{+}$cells in the periodontal ligament of adult mouse molars can form the periodontal ligament, cementum, and alveolar bone. They support the renewal and injury repair of periodontal tissue, and their activity is modulated by canonical Wnt signaling (Men et al., 2020). In Gli1-CreERT2; tdTomato mice, metaphyseal mesenchymal progenitor cells $\left(\mathrm{Gli1}^{+}\right.$cells) dissociated from metaphyseal trabecular bone, are clustered into four subsets: osteoblasts, pre-osteoblasts, chondrocyte-like osteoprogenitor, and marrow adipogenic lineage progenitors, among which chondrocyte-like osteoprogenitor is a potential target for widespread bone anabolic drug, teriparatide, and expresses the high levels of growth-related factors such as $\mathrm{Hh}$ target genes and IGF-1 (Laron, 2001; Shi et al., 2021).

PDGFR $\beta$ is involved in the maintenance of immature and proliferative states for skeletal stem/progenitor cells (SSPCs). $P d g f r \beta$-traced cells were displayed in the growth plate, metaphyseal, periosteal, BMSCs, and perivascular space inhabited by osteo-primed multipotential stem cells (Bohm et al., 2019). In Pdgfrb-CreERT2; Rosa26-mTmG mice, long bone-derived $\mathrm{GFP}^{+}$cells belonged to three major subpopulations (BMSCs, chondrocytes, and smooth muscle cells) and two minor subsets (fibroblasts and hematopoietic cells). Trajectory analysis and in vitro culture of $\mathrm{GFP}^{+} \mathrm{BMSC}$ support $P d g f r \beta^{+}$BMSCs possessing trilineage differentiation potential (Bohm et al., 2019). PDGFR $\beta$ promotes osteogenesis and angiogenesis in the postnatal period and activates SSPC in injury. Following a fracture, reparative SSPCs in the periosteal, endosteal and perivascular spaces were activated and recruited under the regulation of Pdgfr $\beta$ signaling. In $P d g f r \beta^{+}$cell-ablated mice, the length of the femur and the number of $\mathrm{Osx}^{+}$ osteoprogenitors decreased (Liu et al., 2013). In contrast, overexpression of human $P d g f r \beta$ led to increased vessels, Pdgfr $\beta^{+}$mpMSCs, and osteoprogenitors (Bohm et al., 2019).

Osteoclasts secrete a cysteine protease called cathepsin $\mathrm{K}$ (CTSK) which plays an important role in the degradation of matrix collagen during bone resorption. Several studies have shown that $C t s k^{+}$cells possess progenitor/stem cell properties (Han et al., 2019). Yang et al. (2013) illustrated that chondroid neoplasms originate from the Ctsk-Cre labeled cell population in perichondrial groove of Ranvier, which exhibits markers and functional characteristics comparable to mesenchymal progenitors. Further studies have shown that $C t s k^{+}$periosteal 
cells contain stem cell populations that mediate intramembranous osteogenesis. ScRNA-seq performed on Ctsk + cells derived from Ctsk-cre; mTmG reporter mouse femurs generated four clusters: expressing osteoblast markers, MSCs marker, stem cell antigen 1 (Sca1), and Acta2, respectively. Monocle-inferring differentiation trajectory showed that MSCs markers were expressed in the prophase of trajectory map containing periosteal stem cells, which supports the existence of stem/progenitor cells among Ctsk ${ }^{+}$cells (Debnath et al., 2018).

As a chemotactic protein, CXCL12 serves as an influential regulator of the musculoskeletal niche. It predominantly acts through the G-coupled protein receptor (CXCR4) and is involved in the conscription, location, growth, and fate determination of hematopoietic and MSCs in the musculoskeletal system (Wright et al., 2005; Hosogane et al., 2010; Fujio et al., 2011). Compared with immature MSCs, alkaline phosphatase-expressing differentiated osteogenic cells displayed decreased Cxcl12 expression levels (Gilbert et al., 2019). CXCL12 is involved in the early differentiation of pre-osteoblast MSCs, but as the cell matures, the scale of involvement of CXCL12 gradually reduced. As a result, if CXCL12 signaling is disrupted, reduced migration and differentiation may ensue, potentially leading to a reduction in the quantity and viability of progenitor cells (Zhang et al., 2008; Guang et al., 2013). CXCL12-GFP ${ }^{+}$BM cells from Cxcl12 ${ }^{\mathrm{GFP} /+}$; CXCL12-creER; R26RtdTomato mice were divided into three categories, stromal, endothelial, and periosteal at P28. $\mathrm{CXCL} 12^{+}$stromal cell consisted of three clusters, two of which were reticular cells and osteogenic progenitors, expressing preadipocyte markers (Adipoq and LepR) and pre-osteoblast markers (Alpl and Postn), respectively. Upon the induction of injury, quiescent CXCL12-creER ${ }^{+}$BMSCs were recruited to the cortical defect, converted into SSC-like state through the regulation of canonical Wnt signaling components, and then differentiated into cortical bone, which does not occur in homeostasis (Matsushita et al., 2020).

As an endocrine hormone, leptin participates in energy metabolism and regulates the promotion and inhibition of MSCs osteogenesis. Previous studies have indicated that leptin enhances BMSC adipogenesis at the expense of osteogenesis, whereas it can promote osteogenesis of cultured MSC in other study (Thomas et al., 1999; Ambati et al., 2010). LepR is a marker that highly enriched BMSCs (Zhou et al., 2014). With trilineage differentiation potential, LepR-expressing cells can give rise to osteocytes, chondrocytes, and adipocytes through in vitro culture and xenotransplantation. Lineage tracing showed that $L e p R^{+}$cells are not only the main source of osteocytes and adipocytes in the adult bone marrow but also a cell reservoir of endochondral osteogenesis during embryonic and postnatal bone formation (Yue et al., 2016). Shen et al. (2021) revealed that an osteogenic growth factor, osteolectin, marked peri-arteriolar rapidly dividing Lep $R^{+}$osteogenic progenitor cells, which increased after injury and depleted during aging. During injury repair, $L e p R^{+}$cells form new chondrocytes and osteoblasts, whereas leptin inhibits bone regeneration by negatively regulating bone marrow osteogenesis (Zhou et al., 2014). LepR $R^{+}$MSCs labeled in LepR-cre; LoxPtdTomato mice possessed potential for both adipogenesis and osteogenesis. The subpopulation clustered by $\operatorname{LepR}^{+}$cells
scRNA-seq analysis showed high levels of adipogenesis- and osteogenesis-associated markers, respectively (Tikhonova et al., 2019). Furthermore, osteo-primed $L_{e p} R^{+}$cells were highly correlated with multipotential human $C D 45^{-} C D 271^{+}$BMSCs (Ghazanfari et al., 2016), and adipocytic-primed $L e p R^{+}$cells were the main pro-hematopoietic factor supplier in the BM niche. In response to stress hematopoiesis, adipogenesis-related pathways in $L e p R^{+}$cells significantly increased, and the expansion of adipocytes was observed after bone marrow insult. In contrast, the expression of ossification-related genes was decreased (Tikhonova et al., 2019).

Genetic lineage tracing based on Cre-loxP system is powerful and widely used in tracking stem cell differentiation and fate. However, single MSC markers are not specific to stem cell populations, making the reliability of this system still debatable. Dual-recombinase-activated lineage tracing (DeaLT) technology introduces the Dre-rox recombination system into the traditional Cre-loxP recombination system, allowing the more precise definition and tracking of cell populations, significantly improving the resolution of lineage fate maps. Different permutations and combinations of Dre-rox and Cre-loxP in the genome can produce different effects, mainly including the following three type: 1) $\mathrm{Cre}^{+} \mathrm{Dre}^{+}$, requires two promoters to drive Dre and Cre to recombination, mainly labeling the doublepositive cells. 2) $\mathrm{Cre}^{+} \mathrm{Dre}^{-}$or $\mathrm{Cre}^{-} \mathrm{Dre}^{+}$, highlight the exclusivity of the two recombination systems, mainly labeling single marker positive cells. 3) $\mathrm{Cre}^{+} \mathrm{Dre}^{+} / \mathrm{Cre}^{-} \mathrm{Dre}^{+}$or $\mathrm{Cre}^{+} \mathrm{Dre}^{+} / \mathrm{Cre}^{+} \mathrm{Dre}^{-}$, mark the double-positive cells, and the cross-section is read out by one of the two markers. More detailed review information has been presented by Zhao and Zhou et al. (2019). This technology has been applied to reveal the developmental origin of hepatic vasculature and the cell fate of club cells, AT2 cells and bronchoalveolar stem cells in the process of lung repair and regeneration (Zhang et al., 2016; Liu et al., 2020). However, few MSC-related studies are using DeaLT technology (Shu et al., 2021). The combined application of DeaL technology and single-cell technology will bring more precise and reliable interpretations on the heterogeneity of MSCs, and facilitate understanding of the regulatory network that controls cell state, which exhibits extensive application prospects and warrant further exploration.

\section{SINGLE-CELL ANALYSIS OF MSC IN RESPONSE TO MICROENVIRONMENT}

The MSC niche supports the self-renewal and multi-lineage differentiation of MSCs. Distinct cell populations in the stem cell microenvironment provide signaling molecules for properly maintaining the proliferation and differentiation of stem cells, which are necessary for tissue stability. MSCs are heterogeneous, and the surrounding niche cells have different metabolic states. MSC will adapt to different microenvironments and perform specific functions through reprogramming. At present, with the help of single-cell sequencing technology, scientists can obtain gene expression profiles of MSC and surrounding niche cells, dissect the metabolic information of different cell types, evaluate 


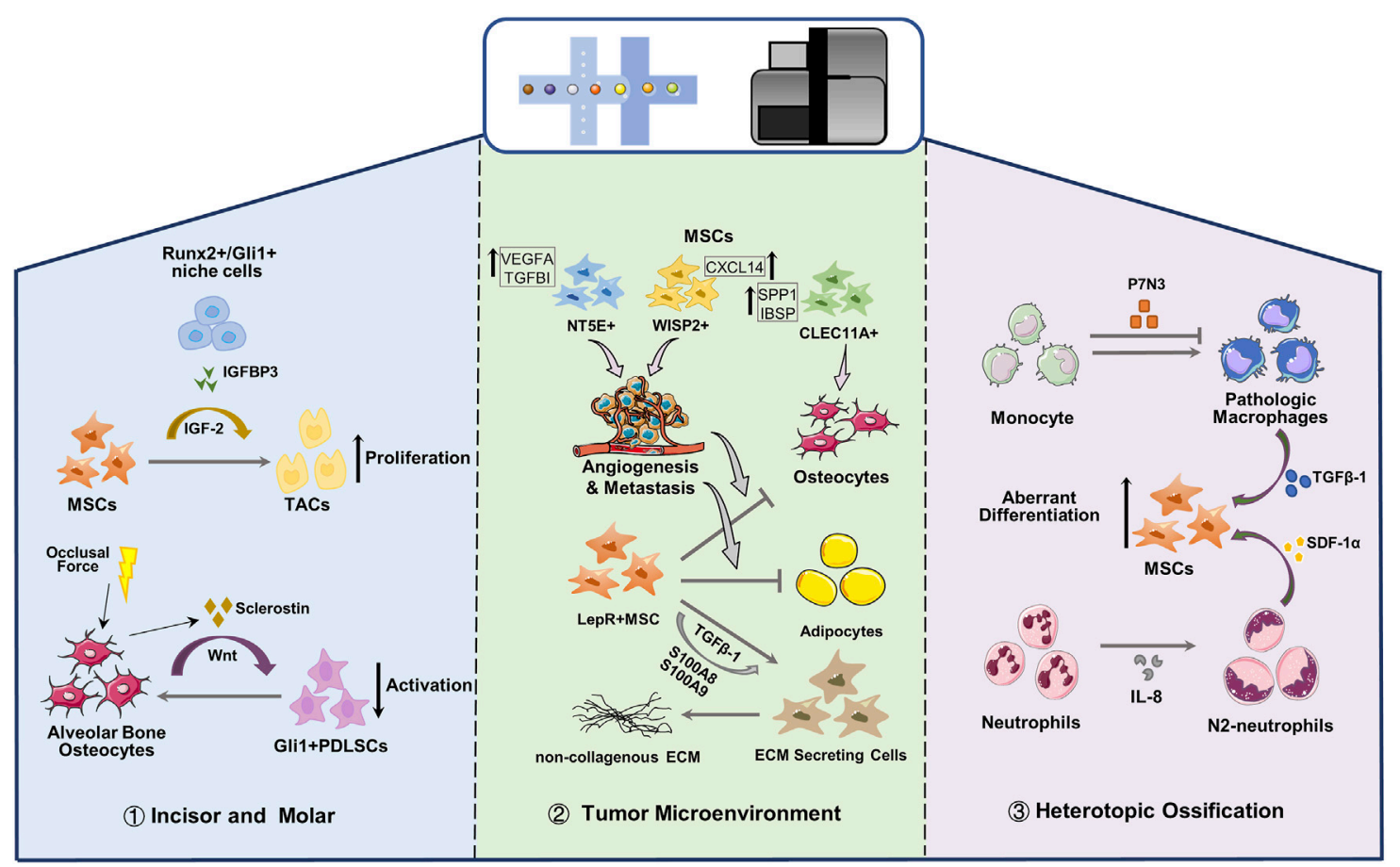

FIGURE 3 | Single cell reveals the crosstalk between MSCs and microenvironment. MSC, Mesenchymal stem cells; TAC, transit-amplifying cells; PDLSC, periodontal ligament stem cells; ECM, extracellular matrix.

the interaction between MSC and the microenvironment, and then study the genetic and environmental factors of MSC at the single-cell level.

\subsection{Tooth Niche Cell Regulates MSCs Homeostasis}

In the dental mesenchyme, Gli1 is typical marker of MSCs in the mouse incisor and RUNX2 is an important transcription factor that regulates bone and tooth development. In adult mouse incisor, most Gli1 and Runx2 co-expressing cells were clustered into a subgroup located proximal region of dental mesenchyme and were adjacent to transit-amplifying cells, which suggested niche cell identity (Chen et al., 2020). Run $2^{+} / \mathrm{Gli1}^{+}$niche cells secrete Insulin-like growth factorbinding protein 3 , thereby activating the exp-mediated IGF2 signaling pathway and coordinating the transition of MSCs to transit-amplifying cells, thereby regulating the proliferation and differentiation of transit-amplifying cells, maintaining the homeostasis of mesenchymal tissue, and controlling the growth rate of incisors (Chen et al., 2020). In addition, studies have shown that osteogenesis in long bones or alveolar bone is governed by sclerostin and mechanical loading (Robling et al., 2008; Men et al., 2020). For the periodontal ligament, the activation and maintenance of $\mathrm{Gli1}^{+}$PDLSCs are modulated by canonical Wnt signaling, whereas alveolar bone cells that secrete sclerostin inhibit Wnt signaling and negatively modulate PDLSC activity (Men et al., 2020). Physiological occlusal force controlling the expression of sclerostin is indirectly involved in the activity of PDLSCs, and this mechano-response is essential for Gli1 $^{+}$PDLSCs activation (Figure 3).

\subsection{The Lineage Transition of MSCs in Senescent}

Aging is accompanied by the accumulation of genetic damage, leading to changes such as mutation, telomere shortening, cellular senescence, and stem cell depletion, etc. As the source of cells in bone marrow, MSC maintains bone metabolism. However, with the increase of age, MSCs tend to differentiate into adipocytes and decreased osteogenesis, leading to an increased risk of agingrelated bone diseases for the elderly, and taking a long time to heal fractures (Woods and Guezguez, 2021). Experiments have shown that senescent MSCs exhibit reduced clonal formation and proliferation capabilities compared to young donor-derived MSCs in vivo and lineage tracing in vitro demonstrated an age-dependent lineage transition between osteogenesis and adipogenic differentiation (Sui et al., 2020). To define MSCs at young, adult, and aging stages, Zhong et al. (2020) performed single-cell sequencing of $\mathrm{Col}^{+}$cells in the long bones of 1,3 , and 16-month-old mice, and divided the MSCs into three subgroups. Pseudotime trajectory inferred that the early mesenchymal progenitors (EMPs) in the three subgroups are the ancestors of two other subgroups expressing Sca1, Thy1 and Cd34, and the next ones are the intermediate mesenchymal progenitor cells and late mesenchymal progenitors respectively. Consistent with the results of CFU-F, the number of MSCs with osteogenic/ adipogenic capabilities in the bone marrow of aging mice 
shrank sharply, while the number of adipocytes greatly increased. In young and adult mice, the intermediate and late mesenchymal progenitor clusters are concentrated at the starting point of differentiation. In the elderly, the loss of intermediate mesenchymal progenitor was observed. MSCs were prone to differentiation, and adipocyte markers such as CBPA and $L P L$ were also highly expressed, which indicated that aged EMPs not only decrease in number but also drift towards a more adipogenic state. The expression of adult MSC marker Lepr in 16-month-old EMPs was significantly higher than that of 1 month, which was consistent with the previously observations that Lepr-Cre labeled MSCs only appeared in the bone marrow of adult mice, but not in young mice (Zhou et al., 2014; Zhong et al., 2020).

\subsection{MSCs Under the Crosstalk With Tumor Microenvironment}

Due to the aggressive growth of tumors, MSCs with regenerative capacity are recruited into lesions for tissue repair. In addition, the increased acidification, nutritional deficiency, inflammatory, hypoxia, and tumors microenvironment (TME) lead MSCs to accumulate in lesions. CXCR4 and Matrix Metalloproteinases 2 (MMP2) participate in the migration process of MSC to TME (Song and Li, 2011). After being recruited to the tumor, the crosstalk between MSCs and cancer cells reshapes the expression pattern of MSCs, thereby changing the direction of differentiation and adapting to the TME by acquiring certain functions, and this crosstalk also changes the metastatic potential and invasion efficiency of cancer cells (Whiteside, 2018). BMSCs promote breast carcinoma cells to produce lysyl oxidase, leading to increased metastatic potential and invasive activity of cancer cells (El-Haibi et al., 2012). In TME, MSCs are induced to differentiate into fibroblasts or myofibroblasts, which stabilize tumor tissue and enhance chemotherapy resistance and cancer stemness (Quante et al., 2011). TME-derived TGF- $\beta 1$ activates MSCs to form cancer-associated fibroblasts-like phenotype. BMSC secrete a series of tumor suppressor factors such as DKK-1/3, interferon, CXCL10, IL12, etc. Dickkopf-1 (DKK-1) as a negative regulator of the $\mathrm{Wnt} / \beta$-catenin pathway endow MSCs with anti-proliferation and anti-tumor effects on erythroleukemic and breast cancer cells (Thiago et al., 2010; Kim et al., 2015). BMSC derived-extracellular vesicles inhibit proliferation and promote apoptosis of liver carcinoma, Kaposi's sarcoma and ovarian tumor cell line (Takahara et al., 2016). The distinction between cancer-promoting MSCs and anti-tumor MSCs may be related to its heterogeneity in TME and the type of cancer. Therefore, it is necessary to explore the heterogeneity of MSC in TME.

Zhou et al. (2020) performed scRNA-seq on osteosarcoma lesions, and the identified clusters are all the progeny of MSC or hematopoietic stem cells. Malignant osteoblastic cells in osteosarcoma can be derived from any cell type in osteogenic lineage of MSCs. MSC cells characterized by MMe, THY1 and CXCL12 are divided into three subgroups $\left(\mathrm{NT}_{5} \mathrm{E}^{+}, \mathrm{WISP}^{+}\right.$and $C L E C 11 A^{+}$), and are present in different types of osteosarcoma lesions (Figure 3). NT5E $E^{+}$MSCs is mainly observed in chondroblastic osteosarcoma lesions which stimulate the angiogenesis and metastasis of osteosarcoma cells; MSCs with high expression of WISP and CXCL14 are regarded to promote the metastasis of osteosarcoma cells and the proliferation of MSCs; CLEC11A ${ }^{+}$MSCs mainly exist in osteoblast osteosarcoma lesions with highly expressing osteoblast differentiation markers (SPP1 and IBSP). Although more efforts are required to reveal the influence of MSCs on malignant osteoblasts and chondrocytes in osteosarcoma lesions, gene expression data suggest that MSCs can help osteosarcoma cells to metastasize or proliferate (Zhou et al., 2020).

MSCs are the main members of the bone marrow niche, which can regulate hematopoietic stem cells and supply hormones and nutrition, and are closely related to various myeloid malignancies. The bone marrow niche under myeloid disease will reshape the transcription of MSCs, enabling lineage transfer and function reprogramming, and making it a potential target for the treatment of myeloid diseases. MSC has become a promising therapeutic tool for many clinical applications due to its unique immunomodulatory properties, which can secrete cytokines, reduce inflammation and cell apoptosis, and promote the proliferation of stem progenitor cells in endogenous tissues and organs (Sivanathan and Coates, 2018; Qin and Zhao, 2020; He et al., 2021b). In primary leukemia, the osteogenic Lepr-MSCs decreased, and the pre-osteoblasts in the OLC subgroup increased significantly (Baryawno et al., 2019). The osteogenic genes in Lepr-MSCs and OLC were down-regulated, and the genes that inhibit bone formation and calcification were up-regulated. The adipogenic genes in Lepr-MSCs were significantly down-regulated, resulting in the obstructed development of osteogenic lineage cells (Figure 3), the damaged adipocytes niche, and the loss of hematopoietic stem cells niche factors, leading to a niche that is not conducive to the production of normal blood cells (Baryawno et al., 2019). Besides, Adipogenic and osteogenic Lepr ${ }^{+}$MSCs are considered to be the main driving factors of myelofibrosis in myeloproliferative neoplasms (Koschmieder and Chatain, 2020). In Thrombopoietin-induced BM fibrosis, LepR and Gli1 labeled adipogenic and osteogenic MSC clusters significantly upregulate non-collagenous extracellular matrix (ECM) specific genes, and down-regulate MSC markers, which leaded to the loss of progenitor cell status and were reprogrammed into ECM secreting cells (Figure 3) (Leimkuhler et al., 2021). Expression profiles and pseudo-time trajectories showed that adipo- and osteo-primed MSC clusters exhibited high level adipogenic (Adipoq) and osteogenic $(S p 7, I b s p)$ signature, and were inferred to be pluripotent precursor cells. With the development of fibrosis, MSC marker genes and hematopoietic support genes were significantly down-regulated in all MSC clusters, while secreted factors (S100A8, S100A9) and genes related to ECM synthesis were significantly up-regulated, indicating that they lost the ability to support hematopoiesis and excessive maldifferentiation, resulting in exorbitant deposition of ECM in the bone marrow (Leimkuhler et al., 2021). MSC-mediated inflammation is the main driving force for the transition of the fibrotic lineage, especially S100A8/ S100A9 pro-inflammatory factors expressed by MSCs and the 
TGF-b signaling pathway. The novel small-molecule tumor suppressor, Tasquinimod, can inhibit S100A8/S100A9 signal transduction and effectively ameliorate fibrosis and the phenotype of myeloproliferative neoplasms (Leimkuhler et al., 2021).

\subsection{Injury-Induced Niche Regulates MSC Behavior}

In the musculoskeletal trauma site, inflammation niches recruit and orchestrate MSCs and immunocytes. MSCs attempt to regenerate tissues according to the prompts of inflammation and the immune microenvironment and sometimes lead to the abnormal cell fate of MSCs, resulting in heterotopic ossification (HO) (Figure 3). Fiber/ adipogenic progenitor, a population of pluripotent stem cells, are the main contributors of $\mathrm{HO}$, expressing PDGFRa and other MSC maker, which exhibits potential for adipogenic, chondrogenic and osteogenic differentiation (Lees-Shepard et al., 2018; Eisner et al., 2020). Fibrous/adipogenic progenitor cells can produce pivotal growth factors and matrix or matrisome proteins, such as IGF-1, TGF- $\beta$, collagens, integrins, etc., which impact the cellular physiology during injury, disease and homeostasis (Biferali et al., 2019; Theret et al., 2021). Recently, Sorkin et al. (2020) used singlecell transcriptome and trajectory analyses to identify different monocyte/macrophage subpopulations after injury and their dynamic changes in the different stages of inflammation after injury. They discovered a cluster of Pdgfra labeled-stromal cells, and the abnormal differentiation of chondrogenic progenitor cell was predetermined 3 days after injury. After burn/tenotomy injury, p7N3 (transforming growth factor-1 expression regulator) treatment altered macrophage subset phenotypes. In addition, the expression levels of chondrogenic and osteogenic markers (Sox9, Runx2, Acan and Col2a1) of the stromal cell clusters in the p7N3 treatment groups are lower than control. They revealed that monocytes/macrophages expressing transforming growth factor-1 play an important role in endochondral osteogenesis-driven mesenchymal chondrogenic progenitor cell abnormal differentiation during $\mathrm{HO}$ progression. (Sorkin et al., 2020). Furthermore, Cai et al. (2021) found that a certain level of interleukin-8 (IL-8) polarizes neutrophils toward the N2 phenotype, which initiates bone regeneration by secreting stromal cell-derived factor-1 $\alpha$ and initiating its downstream cascade reaction to mediate BMSC recruitment and differentiation, thereby inducing ectopic endochondral ossification.

\section{CONCLUSION AND FUTURE PERSPECTIVES}

In this review, we summarized the heterogeneity of human and mouse MSCs at single-cell resolution from embryo development to adulthood and emphasized subsets with osteogenic potential. During the initial stage of embryonic limb buds, the subpopulations of limb bud MSCs exhibit continuous marker expression patterns and uniquely respond to morphogenesis gradient signals and bone-forming signals, thereby displaying distinct differentiation states and osteogenic activity in different limb bud regions. Among them, subgroups marked by transient high expression marker genes require much weighted attention, in which phased transcription patterns in these subgroups have important consequences for musculoskeletal development. More nuanced analyses are needed to fully understand the changes in cell transcription during the development process, as well as the impact and significance of its existence. ScRNA-seq has identified stem/ progenitor cell subsets with osteogenic potential in various cell types of hard tissues, including dental pulp/periodontal stem cells, bone marrow/periosteal stromal cells, chondrocytes, and craniofacial suture mesenchymal stem cells (Zhao et al., 2015; Mizuhashi et al., 2018; Tikhonova et al., 2019; Pagella et al., 2021). Unlike MSCs, SSCs identified in bone marrow have no adipogenic ability, and exclusively generate osteogenic lineages. Although many of the above-mentioned osteogenic cell subsets are called as MSCs, they may still retain adipogenic and myogenic potential. At present, the term, "skeletal stem cells", is under continuous refinement, the relationship and underlying molecular differences between SSCs and MSCs cannot be clearly defined yet. Similar to hematopoiesis, osteogenic stem cells also depend on the mediation of niche-derived signals, extracellular matrix, and cytokines. However, compared with the hematopoietic stem cell niche, studies on MSC microenvironment are relatively lacking. In addition to inflammatory microenvironment, the interaction between stem cells and surrounding niche cells is also largely unelucidated, when the crucial phase transitions of bone-forming pattern, especially during bone growth spurt in puberty and aging-related osteoporosis.

Besides scRNA-seq, single-cell technology includes single-cell ChIP-seq and ATAC-seq, etc., which allow the detection of intercellular heterogeneity and can comprehensively reveal interactions between cell movement, signal transduction pathways, transcription factors, and genome chromatin packaging, to deeply characterize stem cell populations in various tissues. Nonetheless, the main obstacle of single-cell technology is the loss of all the spatial information of the original cells. Recently emerging spatial transcriptome technology has swept the obstacle away, which allows the analysis of transcriptome information while preserving the spatial location of the tissue section (Liao et al., 2021). The integration of spatiotemporal information and single-cell transcriptomics pave the way for identifying the pivotal distinctions between cell subtypes and in-depth analysis of developmental tissues and is expected to bring new insights into MSCs.

\section{AUTHOR CONTRIBUTIONS}

FS wrote the original manuscript and designed figures. YS designed the project and revised the article.

\section{FUNDING}

This work was supported by the funding of National Natural Science Foundation of China (Grant/Award Number: 82071091 to YS) and Sichuan Science and Technology Program (Grant/ Award Number: 2020ZYD001 to YS). 


\section{REFERENCES}

Ai, S., Xiong, H., Li, C. C., Luo, Y., Shi, Q., Liu, Y., et al. (2019). Profiling Chromatin States Using Single-Cell itChIP-Seq. Nat. Cel Biol. 21, 1164-1172. doi:10.1038/ s41556-019-0383-5

Akiyama, H., Kim, J.-E., Nakashima, K., Balmes, G., Iwai, N., Deng, J. M., et al. (2005). Osteo-Chondroprogenitor Cells Are Derived from Sox9 Expressing Precursors. Proc. Natl. Acad. Sci. 102, 14665-14670. doi:10.1073/ pnas.0504750102

Al-Sabah, J., Baccin, C., and Haas, S. (2020). Single-Cell and Spatial Transcriptomics Approaches of the Bone Marrow Microenvironment. Curr. Opin. Oncol. 32, 146-153. doi:10.1097/CCO.0000000000000602

Ambati, S., Li, Q., Rayalam, S., Hartzell, D. L., Della-Fera, M. A., Hamrick, M. W., et al. (2010). Central Leptin versus Ghrelin: Effects on Bone Marrow Adiposity and Gene Expression. Endocrine 37, 115-123. doi:10.1007/ s12020-009-9274-z

Andrews, T. S., Kiselev, V. Y., McCarthy, D., and Hemberg, M. (2021). Tutorial: Guidelines for the Computational Analysis of Single-Cell RNA Sequencing Data. Nat. Protoc. 16, 1-9. doi:10.1038/s41596-020-00409-w

Baryawno, N., Przybylski, D., Kowalczyk, M. S., Kfoury, Y., Severe, N., Gustafsson, K., et al. (2019). A Cellular Taxonomy of the Bone Marrow Stroma in Homeostasis and Leukemia. Cell 177, 1915-1932. doi:10.1016/j.cell.2019.04.040

Biferali, B., Proietti, D., Mozzetta, C., and Madaro, L. (2019). Fibro-Adipogenic Progenitors Cross-Talk in Skeletal Muscle: The Social Network. Front. Physiol. 10, 1074. doi:10.3389/fphys.2019.01074

Blitz, E., Sharir, A., Akiyama, H., and Zelzer, E. (2013). Tendon-bone Attachment Unit Is Formed Modularly by a Distinct Pool of Scx- and Sox9-Positive Progenitors. Development 140, 2680-2690. doi:10.1242/dev.093906

Böhm, A.-M., Dirckx, N., Tower, R. J., Peredo, N., Vanuytven, S., Theunis, K., et al. (2019). Activation of Skeletal Stem and Progenitor Cells for Bone Regeneration Is Driven by PDGFR $\beta$ Signaling. Develop. Cel 51, 236-254. doi:10.1016/ j.devcel.2019.08.013

Cai, B., Lin, D., Li, Y., Wang, L., Xie, J., Dai, T., et al. (2021). N2-Polarized Neutrophils Guide Bone Mesenchymal Stem Cell Recruitment and Initiate Bone Regeneration: A Missing Piece of the Bone Regeneration Puzzle. Adv. Sci. 8, e2100584. doi:10.1002/advs.202100584

Campbell, K. R., and Yau, C. (2018). Uncovering Pseudotemporal Trajectories with Covariates from Single Cell and Bulk Expression Data. Nat. Commun. 9, 2442. doi:10.1038/s41467-018-04696-6

Cao, Y., Buckels, E. J., and Matthews, B. G. (2020). Markers for Identification of Postnatal Skeletal Stem Cells In Vivo. Curr. Osteoporos. Rep. 18, 655-665. doi:10.1007/s11914-020-00622-2

Chaligne, R., Gaiti, F., Silverbush, D., Schiffman, J. S., Weisman, H. R., Kluegel, L., et al. (2021). Epigenetic Encoding, Heritability and Plasticity of Glioma Transcriptional Cell States. Nat. Genet. 53, 1469-1479. doi:10.1038/s41588-021-00927-7

Chan, C. K., Seo, E. Y., Chen, J. Y., Lo, D., McArdle, A., Sinha, R., et al. (2015). Identification and Specification of the Mouse Skeletal Stem Cell. Cell 160, 285-298. doi:10.1016/j.cell.2014.12.002

Chan, C. K. F., Gulati, G. S., Sinha, R., Tompkins, J. V., Lopez, M., Carter, A. C., et al. (2018). Identification of the Human Skeletal Stem Cell. Cell 175, 43-56. doi:10.1016/j.cell.2018.07.029

Chaudhary, R., Lee, M.-S., Mubyana, K., Duenwald-Kuehl, S., Johnson, L., Kaiser, J., et al. (2016). Advanced Quantitative Imaging and Biomechanical Analyses of Periosteal Fibers in Accelerated Bone Growth. Bone 92, 201-213. doi:10.1016/ j.bone.2016.08.021

Chen, S., Jing, J., Yuan, Y., Feng, J., Han, X., Wen, Q., et al. (2020). Runx2+ Niche Cells Maintain Incisor Mesenchymal Tissue Homeostasis through IGF Signaling. Cel Rep. 32, 108007. doi:10.1016/j.celrep.2020.108007

Chen, Y., Yu, Q., Hu, Y., and Shi, Y. (2019). Current Research and Use of Mesenchymal Stem Cells in the Therapy of Autoimmune Diseases. Curr. Stem Cell Res. Ther. 14, 579-582. doi:10.2174/1574888X14666190429141421

Colnot, C. (2009). Skeletal Cell Fate Decisions within Periosteum and Bone Marrow during Bone Regeneration. J. Bone Mineral Res. 24, 274-282. doi:10.1359/jbmr.081003

Debnath, S., Yallowitz, A. R., McCormick, J., Lalani, S., Zhang, T., Xu, R., et al. (2018). Discovery of a Periosteal Stem Cell Mediating Intramembranous Bone Formation. Nature 562, 133-139. doi:10.1038/s41586-018-0554-8
Duchamp de Lageneste, O., Julien, A., Abou-Khalil, R., Frangi, G., Carvalho, C., Cagnard, N., et al. (2018). Periosteum Contains Skeletal Stem Cells with High Bone Regenerative Potential Controlled by Periostin. Nat. Commun. 9, 773. doi:10.1038/s41467-018-03124-Z

Eisner, C., Cummings, M., Johnston, G., Tung, L. W., Groppa, E., Chang, C., et al. (2020). Murine Tissue-Resident PDGFRa+ Fibro-Adipogenic Progenitors Spontaneously Acquire Osteogenic Phenotype in an Altered Inflammatory Environment. J. Bone Miner. Res. 35, 1525-1534. doi:10.1002/jbmr.4020

El-Haibi, C. P., Bell, G. W., Zhang, J., Collmann, A. Y., Wood, D., Scherber, C. M., et al. (2012). Critical Role for Lysyl Oxidase in Mesenchymal Stem Cell-Driven Breast Cancer Malignancy. Proc. Natl. Acad. Sci. 109, 17460-17465. doi:10.1073/pnas.1206653109

Farin, H. F., Lüdtke, T. H.-W., Schmidt, M. K., Placzko, S., Schuster-Gossler, K., Petry, M., et al. (2013). Tbx2 Terminates Shh/Fgf Signaling in the Developing Mouse Limb Bud by Direct Repression of Gremlin1. Plos Genet. 9, e1003467. doi:10.1371/journal.pgen.1003467

Fujio, M., Yamamoto, A., Ando, Y., Shohara, R., Kinoshita, K., Kaneko, T., et al. (2011). Stromal Cell-Derived Factor-1 Enhances Distraction OsteogenesisMediated Skeletal Tissue Regeneration through the Recruitment of Endothelial Precursors. Bone 49, 693-700. doi:10.1016/j.bone.2011.06.024

Ghazanfari, R., Li, H., Zacharaki, D., Lim, H. C., and Scheding, S. (2016). Human Non-Hematopoietic CD271pos/CD140alow/neg Bone Marrow Stroma Cells Fulfill Stringent Stem Cell Criteria in Serial Transplantations. Stem Cell Develop. 25, 1652-1658. doi:10.1089/scd.2016.0169

Gilbert, W., Bragg, R., Elmansi, A. M., McGee-Lawrence, M. E., Isales, C. M., Hamrick, M. W., et al. (2019). Stromal Cell-Derived Factor-1 (CXCL12) and its Role in Bone and Muscle Biology. Cytokine 123, 154783. doi:10.1016/ j.cyto.2019.154783

Guang, L. G., Boskey, A. L., and Zhu, W. (2013). Age-Related CXC Chemokine Receptor-4-Deficiency Impairs Osteogenic Differentiation Potency of Mouse Bone Marrow Mesenchymal Stromal Stem Cells. Int. J. Biochem. Cel Biol. 45, 1813-1820. doi:10.1016/j.biocel.2013.05.034

Han, Y., Feng, H., Sun, J., Liang, X., Wang, Z., Xing, W., et al. (2019). Lkb1 Deletion in Periosteal Mesenchymal Progenitors Induces Osteogenic Tumors through mTORC1 Activation. J. Clin. Invest. 129, 1895-1909. doi:10.1172/JCI124590

He, J., Yan, J., Wang, J., Zhao, L., Xin, Q., Zeng, Y., et al. (2021a). Dissecting Human Embryonic Skeletal Stem Cell Ontogeny by Single-Cell Transcriptomic and Functional Analyses. Cell Res 31, 742-757. doi:10.1038/s41422-021-00467-Z

He, J., Zhang, N., Zhu, Y., Jin, R., and Wu, F. (2021b). MSC Spheroids-Loaded Collagen Hydrogels Simultaneously Promote Neuronal Differentiation and Suppress Inflammatory Reaction through PI3K-Akt Signaling Pathway. Biomaterials 265, 120448. doi:10.1016/j.biomaterials.2020.120448

Herring, C. A., Chen, B., McKinley, E. T., and Lau, K. S. (2018). Single-Cell Computational Strategies for Lineage Reconstruction in Tissue Systems. Cell Mol. Gastroenterol. Hepatol. 5, 539-548. doi:10.1016/j.jcmgh.2018.01.023

Hosogane, N., Huang, Z., Rawlins, B. A., Liu, X., Boachie-Adjei, O., Boskey, A. L., et al. (2010). Stromal Derived Factor-1 Regulates Bone Morphogenetic Protein 2-Induced Osteogenic Differentiation of Primary Mesenchymal Stem Cells. Int. J. Biochem. Cel Biol. 42, 1132-1141. doi:10.1016/j.biocel.2010.03.020

Huang, Y., Li, Q., Zhang, K., Hu, M., Wang, Y., Du, L., et al. (2019). Single Cell Transcriptomic Analysis of Human Mesenchymal Stem Cells Reveals Limited Heterogeneity. Cell Death Dis 10, 368. doi:10.1038/s41419-019-1583-4

Kelly, N. H., Huynh, N. P. T., and Guilak, F. (2020). Single Cell RNA-Sequencing Reveals Cellular Heterogeneity and Trajectories of Lineage Specification During Murine Embryonic Limb Development. Matrix Biol. 89, 1-10. doi:10.1016/ j.matbio.2019.12.004

Killian, M. L., and Thomopoulos, S. (2016). Scleraxis Is Required for the Development of a Functional Tendon Enthesis. FASEB j. 30, 301-311. doi:10.1096/fj.14-258236

Kim, H. Y., Park, J. H., Won, H. Y., Lee, J. Y., and Kong, G. (2015). CBX7 Inhibits Breast Tumorigenicity through DKK-1-mediated Suppression of the Wnt/ $\beta$ Catenin Pathway. FASEB j. 29, 300-313. doi:10.1096/fj.14-253997

Koschmieder, S., and Chatain, N. (2020). Role of Inflammation in the Biology of Myeloproliferative Neoplasms. Blood Rev. 42, 100711. doi:10.1016/ j.blre.2020.100711

Krivanek, J., Soldatov, R. A., Kastriti, M. E., Chontorotzea, T., Herdina, A. N., Petersen, J., et al. (2020). Dental Cell Type Atlas Reveals Stem and 
Differentiated Cell Types in Mouse and Human Teeth. Nat. Commun. 11, 4816. doi:10.1038/s41467-020-18512-7

Kuwahara, S. T., Serowoky, M. A., Vakhshori, V., Tripuraneni, N., Hegde, N. V., Lieberman, J. R., et al. (2019). Sox9+ Messenger Cells Orchestrate Large-Scale Skeletal Regeneration in the Mammalian Rib. eLife 8, e40715. doi:10.7554/ eLife.40715

Laron, Z. (2001). Insulin-like Growth Factor 1 (IGF-1): a Growth Hormone. J. Clin. Pathol.-Mol. Pathol. 54, 311-316. doi:10.1136/mp.54.5.311

Lees-Shepard, J. B., Yamamoto, M., Biswas, A. A., Stoessel, S. J., Nicholas, S.-A. E., Cogswell, C. A., et al. (2018). Activin-Dependent Signaling in Fibro/adipogenic Progenitors Causes Fibrodysplasia Ossificans Progressiva. Nat. Commun. 9, 471. doi:10.1038/s41467-018-02872-2

Leimkühler, N. B., Gleitz, H. F. E., Ronghui, L., Snoeren, I. A. M., Fuchs, S. N. R., Nagai, J. S., et al. (2021). Heterogeneous Bone-Marrow Stromal Progenitors Drive Myelofibrosis via a Druggable Alarmin Axis. Cell Stem Cell 28, 637-652. doi:10.1016/j.stem.2020.11.004

Li, L., Guo, F., Gao, Y., Ren, Y., Yuan, P., Yan, L., et al. (2018). Single-cell MultiOmics Sequencing of Human Early Embryos. Nat. Cel Biol. 20, 847-858. doi:10.1038/s41556-018-0123-2

Lian, J. B., Stein, G. S., Javed, A., van Wijnen, A. J., Stein, J. L., Montecino, M., et al. (2006). Networks and Hubs for the Transcriptional Control of Osteoblastogenesis. Rev. Endocr. Metab. Disord. 7, 1-16. doi:10.1007/s11154006-9001-5

Liao, J., Lu, X., Shao, X., Zhu, L., and Fan, X. (2021). Uncovering an Organ's Molecular Architecture at Single-Cell Resolution by Spatially Resolved Transcriptomics. Trends Biotechnol. 39, 43-58. doi:10.1016/ j.tibtech.2020.05.006

Liu, K., Tang, M., Jin, H., Liu, Q., He, L., Zhu, H., et al. (2020). Triple-Cell Lineage Tracing by a Dual Reporter on a Single Allele. J. Biol. Chem. 295, 690-700. doi:10.1074/jbc.RA119.011349

Liu, Y., Strecker, S., Wang, L., Kronenberg, M. S., Wang, W., Rowe, D. W., et al. (2013). Osterix-Cre Labeled Progenitor Cells Contribute to the Formation and Maintenance of the Bone Marrow Stroma. PLoS One 8, e71318. doi:10.1371/ journal.pone.0071318

Lu, S., and Qiao, X. (2021). Single-Cell Profiles of Human Bone Marrow-Derived Mesenchymal Stromal Cells after IFN- $\gamma$ and TNF- $\alpha$ Licensing. Gene 771, 145347. doi:10.1016/j.gene.2020.145347

Luan, X., Dangaria, S., Ito, Y., Walker, C. G., Jin, T., Schmidt, M. K., et al. (2009). Neural Crest Lineage Segregation: A Blueprint for Periodontal Regeneration. J. Dent. Res. 88, 781-791. doi:10.1177/0022034509340641

Maes, C., Kobayashi, T., Selig, M. K., Torrekens, S., Roth, S. I., Mackem, S., et al. (2010). Osteoblast Precursors, but Not Mature Osteoblasts, Move into Developing and Fractured Bones along with Invading Blood Vessels. Develop. Cel 19, 329-344. doi:10.1016/j.devcel.2010.07.010

Maruyama, T., Jeong, J., Sheu, T.-J., and Hsu, W. (2016). Stem Cells of the Suture Mesenchyme in Craniofacial Bone Development, Repair and Regeneration. Nat. Commun. 7, 10526. doi:10.1038/ncomms10526

Matsushita, Y., Nagata, M., Kozloff, K. M., Welch, J. D., Mizuhashi, K., Tokavanich, N., et al. (2020). A Wnt-Mediated Transformation of the Bone Marrow Stromal Cell Identity Orchestrates Skeletal Regeneration. Nat. Commun. 11, 332. doi:10.1038/s41467-019-14029-w

Men, Y., Wang, Y., Yi, Y., Jing, D., Luo, W., Shen, B., et al. (2020). Gli1+ Periodontium Stem Cells Are Regulated by Osteocytes and Occlusal Force. Develop. Cel 54, 639-654. doi:10.1016/j.devcel.2020.06.006

Michos, O., Panman, L., Vintersten, K., Beier, K., Zeller, R., and Zuniga, A. (2004). Gremlin-mediated BMP Antagonism Induces the EpithelialMesenchymal Feedback Signaling Controlling Metanephric Kidney and Limb Organogenesis. Development 131, 3401-3410. doi:10.1242/ dev.01251

Mizuhashi, K., Nagata, M., Matsushita, Y., Ono, W., and Ono, N. (2019). Growth Plate Borderline Chondrocytes Behave as Transient Mesenchymal Precursor Cells. J. Bone Miner. Res. 34, 1387-1392. doi:10.1002/jbmr.3719

Mizuhashi, K., Ono, W., Matsushita, Y., Sakagami, N., Takahashi, A., Saunders, T. L., et al. (2018). Resting Zone of the Growth Plate Houses a Unique Class of Skeletal Stem Cells. Nature 563, 254-258. doi:10.1038/s41586-018-0662-5

Moore, E. R., Yang, Y., and Jacobs, C. R. (2018). Primary Cilia Are Necessary for Prx1-Expressing Cells to Contribute to Postnatal Skeletogenesis. J. Cel Sci. 131, jcs217828. doi: $10.1242 /$ jcs. 217828
Nakashima, K., Zhou, X., Kunkel, G., Zhang, Z., Deng, J. M., Behringer, R. R., et al. (2002). The Novel Zinc Finger-Containing Transcription Factor Osterix Is Required for Osteoblast Differentiation and Bone Formation. Cell 108, 17-29. doi:10.1016/S0092-8674(01)00622-5

Nam, A. S., Chaligne, R., and Landau, D. A. (2021). Integrating Genetic and NonGenetic Determinants of Cancer Evolution by Single-Cell Multi-Omics. Nat. Rev. Genet. 22, 3-18. doi:10.1038/s41576-020-0265-5

Norrie, J. L., Lewandowski, J. P., Bouldin, C. M., Amarnath, S., Li, Q., Vokes, M. S., et al. (2014). Dynamics of BMP Signaling in Limb Bud Mesenchyme and Polydactyly. Develop. Biol. 393, 270-281. doi:10.1016/j.ydbio.2014.07.003

Ono, N., Ono, W., Mizoguchi, T., Nagasawa, T., Frenette, P. S., and Kronenberg, H. M. (2014). Vasculature-Associated Cells Expressing Nestin in Developing Bones Encompass Early Cells in the Osteoblast and Endothelial Lineage. Develop. Cel 29, 330-339. doi:10.1016/j.devcel.2014.03.014

Ornitz, D. M., and Marie, P. J. (2015). Fibroblast Growth Factor Signaling in Skeletal Development and Disease. Genes Dev. 29, 1463-1486. doi:10.1101/ gad.266551.115

Ortinau, L. C., Wang, H., Lei, K., Deveza, L., Jeong, Y., Hara, Y., et al. (2019). Identification of Functionally Distinct Mx1+aSMA+ Periosteal Skeletal Stem Cells. Cell Stem Cell 25, 784-796. doi:10.1016/j.stem.2019.11.003

Pagella, P., de Vargas Roditi, L., Stadlinger, B., Moor, A. E., and Mitsiadis, T. A. (2021). A Single-Cell Atlas of Human Teeth. iScience 24, 102405. doi:10.1016/ j.isci.2021.102405

Ponte, F., Kim, H. N., Iyer, S., Han, L., Almeida, M., and Manolagas, S. C. (2020). Cxcl12 Deletion in Mesenchymal Cells Increases Bone Turnover and Attenuates the Loss of Cortical Bone Caused by Estrogen Deficiency in Mice. J. Bone Miner. Res. 35, 1441-1451. doi:10.1002/jbmr.4002

Qin, H., and Zhao, A. (2020). Mesenchymal Stem Cell Therapy for Acute Respiratory Distress Syndrome: from Basic to Clinics. Protein Cell 11, 707-722. doi:10.1007/s13238-020-00738-2

Quante, M., Tu, S. P., Tomita, H., Gonda, T., Wang, S. S. W., Takashi, S., et al. (2011). Bone Marrow-Derived Myofibroblasts Contribute to the Mesenchymal Stem Cell Niche and Promote Tumor Growth. Cancer Cell 19, 257-272. doi:10.1016/j.ccr.2011.01.020

Ramos, T. L., Sánchez-Abarca, L. I., Muntión, S., Preciado, S., Puig, N., LópezRuano, G., et al. (2016). MSC Surface Markers (CD44, CD73, and CD90) Can Identify Human MSC-Derived Extracellular Vesicles by Conventional Flow Cytometry. Cell Commun. Signal. 14, 2. doi:10.1186/s12964-015-0124-8

Reinhardt, R., Gullotta, F., Nusspaumer, G., Ünal, E., Ivanek, R., Zuniga, A., et al. (2019). Molecular Signatures Identify Immature Mesenchymal Progenitors in Early Mouse Limb Buds that Respond Differentially to Morphogen Signaling. Development 146, dev173328. doi:10.1242/dev.173328

Robling, A. G., Niziolek, P. J., Baldridge, L. A., Condon, K. W., Allen, M. R., Alam, I., et al. (2008). Mechanical Stimulation of Bone In Vivo Reduces Osteocyte Expression of Sost/Sclerostin. J. Biol. Chem. 283, 5866-5875. doi:10.1074/ jbc.M705092200

Severe, N., Karabacak, N. M., Gustafsson, K., Baryawno, N., Courties, G., Kfoury, Y., et al. (2019). Stress-Induced Changes in Bone Marrow Stromal Cell Populations Revealed through Single-Cell Protein Expression Mapping. Cell Stem Cell 25, 570-583. e7. doi:10.1016/j.stem.2019.06.003

Sharpe, P. T. (2016). Dental Mesenchymal Stem Cells. Development 143, 2273-2280. doi:10.1242/dev.134189

Shen, B., Tasdogan, A., Ubellacker, J. M., Zhang, J., Nosyreva, E. D., Du, L., et al. (2021). A Mechanosensitive Peri-Arteriolar Niche for Osteogenesis and Lymphopoiesis. Nature 591, 438-444. doi:10.1038/s41586-021-03298-5

Shi, Y., He, G., Lee, W.-C., McKenzie, J. A., Silva, M. J., and Long, F. (2017). Gli1 Identifies Osteogenic Progenitors for Bone Formation and Fracture Repair. Nat. Commun. 8, 2043. doi:10.1038/s41467-017-02171-2

Shi, Y., Liao, X., Long, J. Y., Yao, L., Chen, J., Yin, B., et al. (2021). Gli1+ Progenitors Mediate Bone Anabolic Function of Teriparatide via Hh and Igf Signaling. Cel Rep. 36, 109542. doi:10.1016/j.celrep.2021.109542

Shu, H. S., Liu, Y. L., Tang, X. T., Zhang, X. S., Zhou, B., Zou, W., et al. (2021). Tracing the Skeletal Progenitor Transition during Postnatal Bone Formation. Cell Stem Cell 28, 2122-2136. doi:10.1016/j.stem.2021.08.010

Sivanathan, K. N., and Coates, P. T. (2018). IL-17A-Induced Mesenchymal Stem Cells Have Promising Therapeutic Value for Clinical Translation. Kidney Int 93, 771-773. doi:10.1016/j.kint.2017.12.010 
Sivaraj, K. K., Jeong, H.-W., Dharmalingam, B., Zeuschner, D., Adams, S., Potente, M., et al. (2021). Regional Specialization and Fate Specification of Bone Stromal Cells in Skeletal Development. Cel Rep. 36, 109352. doi:10.1016/ j.celrep.2021.109352

Song, C., and Li, G. (2011). CXCR4 and Matrix Metalloproteinase-2 Are Involved in Mesenchymal Stromal Cell Homing and Engraftment to Tumors. Cytotherapy 13, 549-561. doi:10.3109/14653249.2010.542457

Sorkin, M., Huber, A. K., Hwang, C., Carson, W. F., Menon, R., Li, J., et al. (2020). Regulation of Heterotopic Ossification by Monocytes in a Mouse Model of Aberrant Wound Healing. Nat. Commun. 11, 722. doi:10.1038/s41467-019$14172-4$

Sui, B.-D., Zheng, C.-X., Li, M., Jin, Y., and Hu, C.-H. (2020). Epigenetic Regulation of Mesenchymal Stem Cell Homeostasis. Trends Cel Biol. 30, 97-116. doi:10.1016/j.tcb.2019.11.006

Takahara, K., Ii, M., Inamoto, T., Nakagawa, T., Ibuki, N., Yoshikawa, Y., et al. (2016). microRNA-145 Mediates the Inhibitory Effect of Adipose TissueDerived Stromal Cells on Prostate Cancer. Stem Cell Develop. 25, 1290-1298. doi:10.1089/scd.2016.0093

Theret, M., Rossi, F. M. V., and Contreras, O. (2021). Evolving Roles of MuscleResident Fibro-Adipogenic Progenitors in Health, Regeneration, Neuromuscular Disorders, and Aging. Front. Physiol. 12, 673404. doi:10.3389/fphys.2021.673404

Thiago, L. S., Costa, E. S., Lopes, D. V., Otazu, I. B., Nowill, A. E., Mendes, F. A., et al. (2010). The Wnt Signaling Pathway Regulates Nalm-16 B-Cell Precursor Acute Lymphoblastic Leukemic Cell Line Survival and Etoposide Resistance. Biomed. Pharmacother. 64, 63-72. doi:10.1016/j.biopha.2009.09.005

Thomas, T., Gori, F., Khosla, S., Jensen, M. D., Burguera, B., and Riggs, B. L. (1999). Leptin Acts on Human Marrow Stromal Cells to Enhance Differentiation to Osteoblasts and to Inhibit Differentiation to Adipocytes1. Endocrinology 140, 1630-1638. doi:10.1210/endo.140.4.6637

Tickle, C., and Towers, M. (2017). Sonic Hedgehog Signaling in Limb Development. Front. Cel Dev. Biol. 5, 14. doi:10.3389/fcell.2017.00014

Tikhonova, A. N., Dolgalev, I., Hu, H., Sivaraj, K. K., Hoxha, E., CuestaDomínguez, Á., et al. (2019). The Bone Marrow Microenvironment at Single-Cell Resolution. Nature 569, 222-228. doi:10.1038/s41586-019-1104-8

Uccelli, A., Moretta, L., and Pistoia, V. (2008). Mesenchymal Stem Cells in Health and Disease. Nat. Rev. Immunol. 8, 726-736. doi:10.1038/nri2395

Wang, Q., Xiong, H., Ai, S., Yu, X., Liu, Y., Zhang, J., et al. (2019). CoBATCH for High-Throughput Single-Cell Epigenomic Profiling. Mol. Cel 76, 206-216. doi:10.1016/j.molcel.2019.07.015

Wei, Y., Sun, H., Gui, T., Yao, L., Zhong, L., Yu, W., et al. (2021). The Critical Role of Hedgehog-Responsive Mesenchymal Progenitors in Meniscus Development and Injury Repair. Elife 10, e62917. doi:10.7554/eLife.62917

Whiteside, T. L. (2018). Exosome and Mesenchymal Stem Cell Cross-Talk in the Tumor Microenvironment. Semin. Immunol. 35, 69-79. doi:10.1016/ j.smim.2017.12.003

Woods, K., and Guezguez, B. (2021). Dynamic Changes of the Bone Marrow Niche: Mesenchymal Stromal Cells and Their Progeny during Aging and Leukemia. Front. Cel Dev. Biol. 9, 714716. doi:10.3389/fcell.2021.714716

Worthley, D. L., Churchill, M., Compton, J. T., Tailor, Y., Rao, M., Si, Y., et al. (2015). Gremlin 1 Identifies a Skeletal Stem Cell with Bone, Cartilage, and Reticular Stromal Potential. Cell 160, 269-284. doi:10.1016/ j.cell.2014.11.042

Wright, L., Maloney, W., Yu, X., Kindle, L., Collinosdoby, P., and Osdoby, P. (2005). Stromal Cell-Derived Factor-1 Binding to its Chemokine Receptor CXCR4 on Precursor Cells Promotes the Chemotactic Recruitment, Development and Survival of Human Osteoclasts. Bone 36, 840-853. doi:10.1016/j.bone.2005.01.021

Xiao, H., Wang, L., Zhang, T., Chen, C., Chen, H., Li, S., et al. (2020). Periosteum Progenitors Could Stimulate Bone Regeneration in Aged Murine Bone Defect Model. J. Cel. Mol. Med. 24, 12199-12210. doi: $10.1111 /$ jcmm.15891

Yang, W., Wang, J., Moore, D. C., Liang, H., Dooner, M., Wu, Q., et al. (2013). Ptpn11 Deletion in a Novel Progenitor Causes Metachondromatosis by Inducing Hedgehog Signalling. Nature 499, 491-495. doi:10.1038/nature12396
Yin, Z., Lin, J., Yan, R., Liu, R., Liu, M., Zhou, B., et al. (2020). Atlas of Musculoskeletal Stem Cells with the Soft and Hard Tissue Differentiation Architecture. Adv. Sci. 7, 2000938. doi:10.1002/advs.202000938

Yu, M., Ma, L., Yuan, Y., Ye, X., Montagne, A., He, J., et al. (2021). Cranial Suture Regeneration Mitigates Skull and Neurocognitive Defects in Craniosynostosis. Cell 184, 243-256. doi:10.1016/j.cell.2020.11.037

Yue, R., Zhou, B. O., Shimada, I. S., Zhao, Z., and Morrison, S. J. (2016). Leptin Receptor Promotes Adipogenesis and Reduces Osteogenesis by Regulating Mesenchymal Stromal Cells in Adult Bone Marrow. Cell Stem Cell 18, 782-796. doi:10.1016/j.stem.2016.02.015

Zelzer, E., Blitz, E., Killian, M. L., and Thomopoulos, S. (2014). Tendon-to-Bone Attachment: From Development to Maturity. Birth Defect Res. C 102, 101-112. doi: $10.1002 /$ bdrc. 21056

Zhang, H., Pu, W., Tian, X., Huang, X., He, L., Liu, Q., et al. (2016). Genetic Lineage Tracing Identifies Endocardial Origin of Liver Vasculature. Nat. Genet. 48, 537-543. doi:10.1038/ng.3536

Zhang, W., Dong, Z., Li, D., Li, B., Liu, Y., Zheng, X., et al. (2021). Cathepsin K Deficiency Promotes Alveolar Bone Regeneration by Promoting Jaw Bone Marrow Mesenchymal Stem Cells Proliferation and Differentiation via Glycolysis Pathway. Cell Prolif 54, e13058. doi:10.1111/cpr.13058

Zhang, W., Ou, G., Hamrick, M., Hill, W., Borke, J., Wenger, K., et al. (2008). AgeRelated Changes in the Osteogenic Differentiation Potential of Mouse Bone Marrow Stromal Cells. J. Bone Miner. Res. 23, 1118-1128. doi:10.1359/ jbmr.080304

Zhao, H., Feng, J., Ho, T.-V., Grimes, W., Urata, M., and Chai, Y. (2015). The Suture Provides a Niche for Mesenchymal Stem Cells of Craniofacial Bones. Nat. Cel Biol. 17, 386-396. doi:10.1038/ncb3139

Zhao, H., and Zhou, B. (2019). Dual Genetic Approaches for Deciphering Cell Fate Plasticity In Vivo: More Than Double. Curr. Opin. Cel Biol. 61, 101-109. doi:10.1016/j.ceb.2019.07.004

Zhong, L., Yao, L., Tower, R. J., Wei, Y., Miao, Z., Park, J., et al. (2020). Single Cell Transcriptomics Identifies a Unique Adipose Lineage Cell Population that Regulates Bone Marrow Environment. eLife 9, e54695. doi:10.7554/eLife.54695

Zhou, B. O., Yue, R., Murphy, M. M., Peyer, J. G., and Morrison, S. J. (2014). Leptin-Receptor-Expressing Mesenchymal Stromal Cells Represent the Main Source of Bone Formed by Adult Bone Marrow. Cell Stem Cell 15, 154-168. doi:10.1016/j.stem.2014.06.008

Zhou, W.-M., Yan, Y.-Y., Guo, Q.-R., Ji, H., Wang, H., Xu, T.-T., et al. (2021). Microfluidics Applications for High-Throughput Single Cell Sequencing. J. Nanobiotechnol. 19, 312. doi:10.1186/s12951-021-01045-6

Zhou, W., Lin, J., Zhao, K., Jin, K., He, Q., Hu, Y., et al. (2019). Single-Cell Profiles and Clinically Useful Properties of Human Mesenchymal Stem Cells of Adipose and Bone Marrow Origin. Am. J. Sports Med. 47, 1722-1733. doi:10.1177/ 0363546519848678

Zhou, Y., Yang, D., Yang, Q., Lv, X., Huang, W., Zhou, Z., et al. (2020). Single-Cell RNA Landscape of Intratumoral Heterogeneity and Immunosuppressive Microenvironment in Advanced Osteosarcoma. Nat. Commun. 11, 6322. doi:10.1038/s41467-020-20059-6

Conflict of Interest: The authors declare that the research was conducted in the absence of any commercial or financial relationships that could be construed as a potential conflict of interest.

Publisher's Note: All claims expressed in this article are solely those of the authors and do not necessarily represent those of their affiliated organizations, or those of the publisher, the editors and the reviewers. Any product that may be evaluated in this article, or claim that may be made by its manufacturer, is not guaranteed or endorsed by the publisher.

Copyright $(02022$ Shen and Shi. This is an open-access article distributed under the terms of the Creative Commons Attribution License (CC BY). The use, distribution or reproduction in other forums is permitted, provided the original author $(s)$ and the copyright owner(s) are credited and that the original publication in this journal is cited, in accordance with accepted academic practice. No use, distribution or reproduction is permitted which does not comply with these terms. 